\title{
The optical properties, physical properties and direct radiative forcing of urban columnar aerosols in the Yangtze River Delta, China
}

\author{
Bingliang Zhuang ${ }^{1}$, Tijian Wang ${ }^{1}$, Jane Liu ${ }^{1,2}$, Huizheng $\mathrm{Che}^{3}$, Yong $\mathrm{Han}^{1}$, Yu Fu ${ }^{4}$, Shu $\mathbf{L i}^{1}$, Min Xie ${ }^{1}$, \\ Mengmeng Li ${ }^{1}$, Pulong Chen ${ }^{1}$, Huimin Chen ${ }^{1}$, Xiu-qun Yang ${ }^{1}$, and Jianning Sun ${ }^{1}$ \\ ${ }^{1}$ School of Atmospheric Sciences, CMA-NJU Joint Laboratory for Climate Prediction Studies, Jiangsu Collaborative \\ Innovation Center for Climate Change, Nanjing University, Nanjing 210023, China \\ ${ }^{2}$ Department of Geography and Planning, University of Toronto, Toronto, M5S 3G3, Canada \\ ${ }^{3}$ Key Laboratory of Atmospheric Chemistry (LAC), Chinese Academy of Meteorological Sciences (CAMS), \\ CMA, Beijing, 100081, China \\ ${ }^{4}$ Dalian Weather Modification Office, Dalian, 116001, China
}

Correspondence: Bingliang Zhuang (blzhuang@nju.edu.cn) and Tijian Wang (tjwang@nju.edu.cn)

Received: 9 March 2017 - Discussion started: 21 June 2017

Revised: 15 November 2017 - Accepted: 27 December 2017 - Published: 1 February 2018

\begin{abstract}
The optical and physical properties as well as the direct radiative forcings (DRFs) of fractionated aerosols in the urban area of the western Yangtze River Delta (YRD) are investigated with measurements from a Cimel sun photometer combined with a radiation transfer model. Ground-based observations of aerosols have much higher temporal resolutions than satellite retrievals. An initial analysis reveals the characteristics of the optical properties of different types of fractionated aerosols in the western YRD. The total aerosols, mostly composed of scattering components $(93.8 \%)$, have mean optical depths of 0.65 at $550 \mathrm{~nm}$ and refractive index of $1.44+0.0084 i$ at $440 \mathrm{~nm}$. The fine aerosols are approximately four times more abundant and have very different compositions from coarse aerosols. The absorbing components account for only $\sim 4.6 \%$ of fine aerosols and $15.5 \%$ of coarse aerosols and have smaller sizes than the scattering aerosols within the same mode. Therefore, fine particles have stronger scattering than coarse ones, simultaneously reflecting the different size distributions between the absorbing and scattering aerosols. The relationships among the optical properties quantify the aerosol mixing and imply that approximately 15 and $27.5 \%$ of the total occurrences result in dustand black-carbon-dominating mixing aerosols, respectively, in the western YRD. Unlike the optical properties, the size distributions of aerosols in the western YRD are similar to those found at other sites over eastern China on a climato-
\end{abstract}

logical scale, peaking at radii of 0.148 and $2.94 \mu \mathrm{m}$. However, further analysis reveals that the coarse-dominated particles can also lead to severe haze pollution over the YRD. Observation-based estimations indicate that both fine and coarse aerosols in the western YRD exert negative DRFs, and this is especially true for fine aerosols $\left(-11.17 \mathrm{~W} \mathrm{~m}^{-2}\right.$ at the top of atmosphere, TOA). A higher absorption fraction leads directly to the negative DRF being further offset for coarse aerosols $\left(-0.33 \mathrm{~W} \mathrm{~m}^{-2}\right)$ at the TOA. Similarly, the coarsemode DRF contributes to only $13.3 \%$ of the total scattering aerosols but $>33.7 \%$ to the total absorbing aerosols. A sensitivity analysis states that aerosol DRFs are not highly sensitive to their profiles in clear-sky conditions. Most of the aerosol properties and DRFs have substantial seasonality in the western YRD. The results further reveal the contributions of each component of the different size particles to the total aerosol optical depths (AODs) and DRFs. Additionally, these results can be used to improve aerosol modelling performance and the modelling of aerosol effects in the eastern regions of China. 


\section{Introduction}

Atmospheric aerosols have a significant influence on air quality, human health and regional/global climate changes. Scientists have suggested that scattering aerosols could greatly offset the warming effects of greenhouse gases (Kiehl and Briegleb, 1993), while absorbing aerosols might further exacerbate global warming (Jacobson, 2002). The global mean direct radiative forcings (DRFs) of scattering aerosols, fossil fuel black carbon (BC) and all aerosols were estimated to be approximately $-0.55,+0.2$ and $-1.04 \mathrm{~W} \mathrm{~m}^{-2}$, respectively (Forster et al., 2007; Reddy et al., 2005), at the top of atmosphere (TOA), thus changing atmospheric circulations and the hydrological cycle in different ways (Menon et al., 2002; Wang et al., 2015).

Many studies on aerosol radiative forcing and its climate effects have been carried out over the past two decades at both global and regional scales, based on model simulations and observations (e.g. Penner et al., 2001; Bellouin et al., 2003; Liao and Seinfeld, 2005; Wu et al., 2012; Wang et al., 2015); however, large uncertainties remain. Forster et al. (2007) noted that the global mean DRF varied from +0.04 to $-0.63 \mathrm{~W} \mathrm{~m}^{-2}$ for total aerosols and from +0.1 to $+0.3 \mathrm{~W} \mathrm{~m}^{-2}$ for $\mathrm{BC}$. The ranges were larger at regional scales, especially in high-aerosol-emission regions (Zhuang et al., 2013a). The DRF uncertainties subsequently result in large biases of the aerosol-related climate effects. There are many factors that affect the simulated radiative forcing, including the aerosol optical properties, which are related to aerosol emissions, size distributions, profiles, compositions and mixing states (Holler et al., 2003; Ma et al., 2017), as well as the surface albedo and clouds ( $\mathrm{Ma}$ and $\mathrm{Yu}, 2012$; Forster et al., 2007). The related uncertainties could be substantially reduced if the observed aerosol optical properties were determined and used (Forster et al., 2007).

With the rapid increase in population and economic growth, air pollutant emissions are much higher in East Asia than in other regions (Zhang et al., 2009). Additionally, dust aerosols from desert regions are always transported to northern and eastern China or even further afield (Wang et al., 2009; Sun et al., 2012; S. Li et al., 2015). Consequently, aerosols in China frequently experience large loadings and complicated compositions and spatial distributions (Zhang et al., 2012), especially in urban agglomerations or megacities (e.g. the Yangtze River Delta, YRD). Therefore, the aerosol optical properties in the YRD must be clarified via observations, which is a premise for accurately estimating the radiative effects of aerosols and for improving aerosol model performance over the eastern region of China. Recently, numerous observation-based studies have been conducted on both surface (e.g. Bergin et al., 2001; Xu et al., 2002; Zhang et al., 2004, 2015; Xia et al., 2007; Yan et al., 2008; He et al., 2009; Fan et al., 2010; Cai et al., 2011; Xu et al., 2012; Wu et al., 2012; Yu et al., 2016; Deng et al., 2016; Zhuang et al., 2017) and columnar (e.g. Chiang et al., 2007; Pan et al., 2010; Yu et al., 2011, 2015; Zhao et al., 2013; Tao et al., 2014; Zhu et al., 2014; Che et al., 2011, 2013, 2014, 2015a, b, c, 2018; Xia et al., 2016; Zheng et al., 2016; Qi et al., 2016) aerosol optical properties (and DRFs), especially in China. However, surface data cannot completely represent the total conditions of aerosols in the atmosphere as these aerosols are highly affected by the variations in boundary layers. The related deficiency could be solved with measurements of the columnar aerosols. For studies of surface aerosols, people mainly focus on the aerosol absorption coefficient (AAC) and scattering coefficient (SC). For columnar aerosol observations, the detailed aerosol optical and physical properties can be obtained, including the aerosol optical depth (AOD), refractive index and Ångström exponent (AE). Che et al. (2015a) introduced a systematic long-term measurement of the countrywide total AOD and AE in China from 2002 to 2013 and indicated that the annual mean AODs were 0.14, 0.74 and 0.54 for rural sites, urban sites and eastern China. There is also some research focusing on the aerosol optical properties in the YRD (Pan et al., 2010; Yu et al., 2011; Zhuang et al., 2014a; Qi et al., 2016). In addition to the aerosol optical properties, the observation-based aerosol DRFs have been estimated around the world (such as those found in Markowicz et al., 2008; Khatri et al., 2009; Kuhlmann and Quaas, 2010; Alam et al., 2011; Zhuang et al., 2014a; Xia et al., 2016). However, almost all these investigations focused on the total aerosol forcing. For example, Xia et al. (2016) stated that the regional mean aerosol DRF in China was approximately -16 to $-37 \mathrm{~W} \mathrm{~m}^{-2}$ at the TOA and approximately -66 to $-111 \mathrm{~W} \mathrm{~m}^{-2}$ at the surface when the solar zenith angle was approximately $60^{\circ}$.

Although considerable studies of the observed columnar aerosol optical properties have been carried out in China and even within the YRD (one of the regions with the fastest urbanization in China), gaps in the current observations remain, especially in the urban areas of those regions with intensive human activity. In the YRD or eastern China, most of the investigations of the aerosol optical properties have focused on the coastal, lake and rural regions (Pan et al., 2010; Yu et al., 2011; Che et al., 2015a; Qi et al., 2016) of the central to eastern YRD. Additionally, most of these studies address only the total aerosol optical properties (independent of modes and compositions), except for the work of Qi et al. (2016). They also introduced the aerosol physical parameters and size fractional SSA of an eastern coastal city (Hangzhou, hereinafter written as urHZ) of the YRD, which is approximately $300 \mathrm{~km}$ away from the western YRD. As implied in Zhang et al. (2012), aerosols have complicated compositions and spatial distributions, especially in rapidly developing regions (such as YRD). Thus, considerable differences might exist in the aerosol optical and physical properties among the sites within the YRD. Additionally, none of research mentioned above studied the aerosol DRFs. Some investigations of the columnar aerosols in the western YRD (urNJ) were carried out by Zhuang et al. (2014a), but sig- 
nificant issues (not considered in their work) still require further study, such as the size fractional optical parameters and the DRFs of different aerosol components, as well as the aerosol physical properties of the different size fractions. Therefore, a more integrated investigation of the aerosol optical and physical properties, as well as their DRFs in the YRD, is still required. In this study, the unaddressed issues for the western and whole YRD region mentioned above will be studied based on the measurements of a Cimel sun photometer in urNJ combined with a radiation transfer model (TUV, Madronich, 1993). Additionally, the aerosol types and mixings in the region will be further identified and discussed based on the relationships among the aerosol optical properties. Thirdly, the observed aerosol profiles, which have not previously been considered in the YRD, are discussed and used to calculate the aerosol DRFs. The results of this study will be advantageous in further understanding the characteristics of aerosols over the eastern region of China. Additionally, this work will help to improve aerosol model performance as well as the modelled climatic effects in the relevant regions. Firstly, the observed aerosol parameters can be used for data assimilation to obtain more accurate inputs (including improved initial conditions and air pollutant emissions) for the model (Jiang et al., 2013; Peng et al., 2017). Secondly, more precise aerosol refractive indexes and size distributions used in these numerical models will yield more reasonable aerosol loadings and DRFs (Ma et al., 2017). Thirdly, both the aerosol optical properties and DRFs can be used to validate the simulations.

The methods are described in Sect. 2. The results and discussions are presented in Sect. 3, followed by the conclusions in Sect. 4.

\section{Methodologies}

\section{Sampling station and instruments}

The observation site (Urban Environmental Monitoring Station of Nanjing University) is located in the downtown area of Nanjing City (hereafter shortened to urNJ; located at $32.05^{\circ} \mathrm{N}, 118.78^{\circ} \mathrm{E}$ ) in the western YRD. The site is on the roof of a $79.3 \mathrm{~m}$ tall building, surrounded by a few higher obstacles and with no industrial pollution sources within a $30 \mathrm{~km}$ radius. However, there are several main roads with apparent traffic pollution. Detailed information about the site is available from Zhu et al. (2012).

The columnar aerosol optical properties and physical characteristics of the site were measured by a Cimel sun photometer (CE-318, Holben et al., 1998) during the period from April 2011 to February 2014. Routine maintenance and calibration was performed during the observational period. Due to malfunctions of the instrument and problems with data transmission, the data from May to September 2012 and from August to December 2013 are invalid and were thus excluded. The wavelength-dependent AOD and AE of the total aerosols were directly measured by CE-318, while the following variables are derived from the DOBVIC algorithm Version 2 (Dubovik and King, 2000; Dubovik et al., 2006): the aerosol size distributions; fractionated (fine and coarse) aerosol effective radius $\left(R_{\text {eff }}\right)$; mean radius $\left(R_{\mathrm{mn}}\right)$, volume concentrations (Vol); wavelength-dependent optical depths of the various sizes of scattering, absorbing and total aerosols; aerosol SSA; and the wavelength-dependent refractive indices, This algorithm has been widely used by the AErosol RObotic NEtwork (AERONET) and the China Aerosol Remote Sensing Network (CARSNET), while the products have been used globally, as mentioned in the Introduction, due to their high accuracies. The errors for the AOD, absorption AOD (AAOD) and SSA are 0.01, 0.01 and 0.03 (Yu et al., 2011; S. Li et al., 2015). The errors of the fineand coarse-aerosol SSAs are 0.037 and 0.085 (Xu, 2015). The errors of the refractive index are 0.04 for the real part and $0.0025-0.0042$ for the imaginary part (Yu et al., 2011). Additionally, the error of the volume size distribution is less than $10 \%$ in the peak regions but is approximately $35 \%$ in valley or interval regions for the fine and coarse modes ( $\mathrm{Yu}$ et al., 2011). Detailed descriptions of CE-318 and the corresponding observations from CARSNET are available from S. Li et al. (2015) and Che et al. (2015a). For comparison, the $550 \mathrm{~nm}$ AODs and SSAs are calculated based on the given AODs at other wavelengths and AEs (Angstrom, 1929):

$$
\begin{aligned}
& \mathrm{AOD}_{550 \mathrm{~nm}}=\mathrm{AOD}_{440 \mathrm{~nm}} \times\left(\frac{550 \mathrm{~nm}}{440 \mathrm{~nm}}\right)^{-\mathrm{AE}_{440 / 870 \mathrm{~nm}}} \\
& \mathrm{AAOD}_{550 \mathrm{~nm}}=\mathrm{AAOD}_{440 \mathrm{~nm}} \times\left(\frac{550 \mathrm{~nm}}{440 \mathrm{~nm}}\right)^{-\mathrm{AAE}_{440 / 870 \mathrm{~nm}}} \\
& \mathrm{SSA}_{550 \mathrm{~nm}}=\frac{\mathrm{AOD}_{550 \mathrm{~nm}}-\mathrm{AAOD}_{550 \mathrm{~nm}}}{\mathrm{AOD}_{550 \mathrm{~nm}}} .
\end{aligned}
$$

For a further comparison, concurrent observations of the surface total $\mathrm{AAC}$ and $\mathrm{AE}$ measured with a 7-channel Aethalometer instrument are used (model AE-31, Magee Scientific, USA, Hansen et al., 1984; Weingartner et al., 2003; Arnott et al., 2005). The detailed calculations and corrections of the AAC at the site were presented by Zhuang et al. (2015). Additionally, the monthly mean AOD and AE of the total aerosols from the satellite-based Moderate Resolution Imaging Spectroradiometer (MODIS) were used in the analysis.

Based on the observed wavelength-dependent aerosol optical properties, the DRF of the aerosols in urNJ is investigated using the radiation transfer model TUV (Madronich, 1993). Only clear-sky DRFs are addressed here because almost all the measurements are carried out in cloud-free-sky conditions. The solar component of the radiative transfer scheme in the TUV model follows the $\delta$-Eddington approximation. In addition to the aerosol optical properties, the surface albedo (Palancar and Toselli, 2004) and aerosol vertical profiles (Forster et al., 2007) might have significant in- 
Table 1. Statistical summary of the columnar aerosol optical properties in the urban area of Nanjing.

\begin{tabular}{|c|c|c|c|c|}
\hline Factors & $\operatorname{Max}$ & Min & Mean \pm SD & Median \\
\hline $550 \mathrm{~nm}$ AOD & 2.3208 & 0.2723 & $0.6494 \pm 0.2852$ & 0.5912 \\
\hline $550 \mathrm{~nm}$ FAOD & 2.2216 & 0.1468 & $0.5257 \pm 0.2806$ & 0.4479 \\
\hline $550 \mathrm{~nm}$ CAOD & 0.9891 & 0.0139 & $0.1237 \pm 0.1076$ & 0.0858 \\
\hline $550 \mathrm{~nm}$ SAOD & 2.2744 & 0.2443 & $0.6059 \pm 0.2747$ & 0.5492 \\
\hline $550 \mathrm{~nm}$ FSAOD & 2.1459 & 0.1435 & $0.5014 \pm 0.2713$ & 0.4263 \\
\hline $550 \mathrm{~nm}$ CSAOD & 0.8842 & 0.0113 & $0.1045 \pm 0.0957$ & 0.0705 \\
\hline $550 \mathrm{~nm}$ AAOD & 0.2304 & 0.0020 & $0.0435 \pm 0.0240$ & 0.0421 \\
\hline $550 \mathrm{~nm}$ FAAOD & 0.1424 & 0.0005 & $0.0244 \pm 0.0175$ & 0.0208 \\
\hline $550 \mathrm{~nm}$ CAAOD & 0.1163 & 0.0009 & $0.0192 \pm 0.0145$ & 0.0156 \\
\hline $440 / 870 \mathrm{~nm} \mathrm{AE}$ & 1.9100 & 0.3085 & $1.2045 \pm 0.2856$ & 1.2436 \\
\hline $440 / 870 \mathrm{~nm}$ FAE & 2.3625 & 0.3565 & $1.7083 \pm 0.2979$ & 1.7364 \\
\hline $440 / 870 \mathrm{~nm}$ CAE & -0.0789 & -0.3805 & $-0.1876 \pm 0.0430$ & -0.1898 \\
\hline $440 / 870 \mathrm{~nm}$ SAE & 1.9916 & 0.2958 & $1.1976 \pm 0.3085$ & 1.2386 \\
\hline $440 / 870$ nm FSAE & 2.3653 & 0.3463 & $1.7102 \pm 0.2980$ & 1.7368 \\
\hline 440/870 nm CSAE & -0.1048 & -0.7111 & $-0.3838 \pm 0.1017$ & -0.3864 \\
\hline $440 / 870 \mathrm{~nm}$ AAE & 3.4619 & 0.1483 & $1.3237 \pm 0.4820$ & 1.2587 \\
\hline 440/870 nm FAAE & 4.5118 & 0.2912 & $1.7521 \pm 0.6470$ & 1.6516 \\
\hline 440/870 nm CAAE & 3.1264 & -0.0844 & $0.8748 \pm 0.4589$ & 0.8209 \\
\hline $550 \mathrm{~nm} \mathrm{SSA}$ & 0.9959 & 0.8053 & $0.9297 \pm 0.0335$ & 0.9305 \\
\hline $550 \mathrm{~nm}$ FSSA & 0.9974 & 0.8388 & $0.9524 \pm 0.0261$ & 0.9549 \\
\hline $550 \mathrm{~nm}$ CSSA & 0.9835 & 0.5898 & $0.8208 \pm 0.0754$ & 0.8225 \\
\hline $440 \mathrm{~nm}$ real part & 1.6000 & 1.3300 & $1.4423 \pm 0.0638$ & 1.4374 \\
\hline $440 \mathrm{~nm}$ imaginary part & 0.0301 & 0.0005 & $0.0084 \pm 0.0047$ & 0.0078 \\
\hline \multicolumn{5}{|c|}{$\begin{array}{l}\text { AOD: Aerosol optical depth. FAOD: fine aerosol optical depth. CAOD: coarse aerosol optical depth. } \\
\text { SAOD: scattering aerosol optical depth. FSAOD: scattering aerosol optical depth in fine mode. } \\
\text { CSAOD: scattering aerosol optical depth in coarse mode. AAOD: absorbing aerosol optical depth. } \\
\text { FAAOD: absorbing aerosol optical depth in fine mode. CAAOD: absorbing aerosol optical depth in coarse } \\
\text { mode. AE: Angström exponent of total aerosols. FAE: Angström exponent of fine aerosols. CAE: Angström } \\
\text { exponent of coarse aerosols. SAE: Angström exponent of scattering aerosols. FSAE: Angström exponent of } \\
\text { scattering aerosols in fine mode. CSAE: Ångström exponent of scattering aerosols in coarse mode. } \\
\text { AAE: Ångström exponent of absorbing aerosols. FAAE: Ångström exponent of absorbing aerosols in fine } \\
\text { mode. CAAE: Angström exponent of absorbing aerosols in coarse mode. SSA: single scattering albedo of } \\
\text { total aerosols. FSSA: single scattering albedo of fine aerosols. CSSA: single scattering albedo of coarse } \\
\text { aerosols. }\end{array}$} \\
\hline
\end{tabular}

fluences on the DRF. Thus, the wavelength-dependent surface albedo from MODIS, the annual and seasonal mean aerosol profiles from the Cloud-Aerosol Lidar and Infrared Pathfinder Satellite Observations (CALIPSO) and the polarization Raman lidar (PRL) in Nanjing are included when assessing the aerosol DRF. The aerosol DRF in this study is defined as the difference in the net shortwave radiative fluxes when including or excluding the aerosol effects at the TOA and surface. The gas absorptions in the atmosphere were set to constant. The scattering aerosol SSA was set to 0.9999 (similar to that of sulfate or nitrate, Li et al., 2015b) when calculating its DRF. The DRF of the absorbing aerosols is derived from the differences between the total and scattering aerosol DRFs.

\section{Results and discussions}

\subsection{Optical properties of the aerosols}

Unless otherwise specified, the AODs, SSAs and refractive indices of the aerosols hereinafter represent the ones at 550,550 and $440 \mathrm{~nm}$, respectively. In addition to the total aerosols, the size-dependent (i.e. the fine and coarse fractions) aerosol optical properties of the different types (scattering and absorbing aerosols) are discussed in this section. Therefore, there are nine types of aerosols: total aerosols (TA), total fine aerosols (FA), total coarse aerosols (CA), scattering aerosols (SA), fine scattering aerosols (FSA), coarse scattering aerosols (CSA), absorbing aerosols (AA), fine absorbing aerosols (FAA) and coarse absorbing aerosols (CAA).

Table 1 summarizes the statistics of the aerosol optical properties during the study period in urNJ. The mean total aerosol AOD is 0.65 , and the SAs account for as much as $93.8 \%$ of this category. Fine-mode AOD (FAOD), finemode scattering AOD (FSAOD) and fine-mode absorbing 

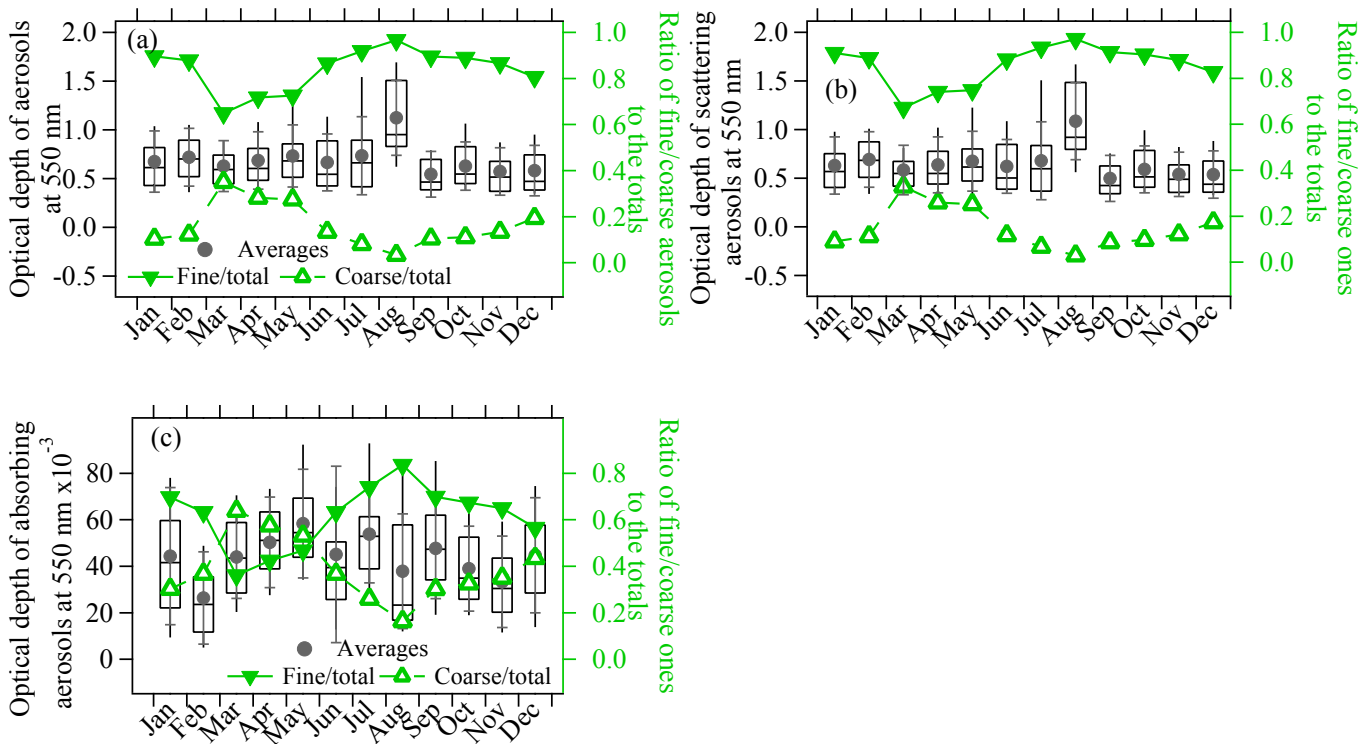

Figure 1. Monthly variations in the total (a), scattering (b) and absorbing (c) aerosol optical depths (AOD) at $550 \mathrm{~nm}$, including the ratio of the AOD in fine or coarse mode to the AOD in all mode (line with triangle markers in green) in the urban area of Nanjing. The 10th, 25th, median, 75th, 90th percentile values of the all mode AOD are presented as box plots. The monthly means of the all mode AODs are presented as cycle markers in grey.

AOD (FAAOD) account for $81.53,81.97$ and $56.09 \%$ of the total AODs, scattering AODs (SAODs) and absorbing AODs (AAODs), respectively, implying that coarse aerosols absorb more than fine ones. The $440 / 870 \mathrm{~nm}$ AE of the total, scattering and absorbing aerosols are approximately 1.20, 1.19 and 1.32. Fine aerosols have much higher AEs, which can be 0.4-0.5 greater than those of the total aerosols. Overall, the absorbing aerosols have smaller sizes than the scattering ones in all modes, especially in the coarse mode, which is consistent with the results from the surface aerosols at the site (Zhuang et al., 2017). The mean SSAs of TA, FA and CA are $0.93,0.95$ and 0.82 , further implying that the coarse aerosols have different compositions than the fine aerosols. The comparisons also indicate that surface aerosols $(\mathrm{SSA}=0.9$ in Zhuang et al., 2017) are slightly more absorptive than the columnar aerosols in urNJ. The mean $440 \mathrm{~nm}$ refractive index is approximately $1.44+0.0084 i$.

\subsubsection{Seasonal variations in the aerosol optical properties}

Figure 1 presents the monthly variations in the (a) AOD, (b) SAOD and (c) AAOD as well as the contributions of their fine and coarse modes to their corresponding totals. The temporal variations in the total aerosol AOD are consistent with those of SAOD due to the significantly large ratio of SAOD/AOD. The AODs are all considerably high in the winter due to the more intense emissions of trace gases and particles (Zhang et al., 2009). Additionally, they are also high in spring and summer under the influences of dust, high efficiencies of mois- ture absorption growth and chemical transformation $(\mathrm{S} . \mathrm{Li}$ et al., 2015). Therefore, the seasonal variations in the total AODs are not so obvious in urNJ in the western YRD. These influences are prominent in the AOD seasonality for different aerosol types within the different size segments. The largest AODs appear in the spring for the coarse aerosols, whereas they appear in the summer for the fine aerosols in urNJ. The figure also implies that the scattering aerosols might have different size distributions than the absorbing aerosols. The fine-mode fraction is 0.83 (peaking at 0.97 ) for scattering aerosols and is 0.56 (peaking at 0.83 ) for absorbing aerosols. Note that AOD in August does not include values in 2012 and 2013. Coincidentally, air pollution has been controlled since 2012 in Nanjing due to international events in August 2013 and 2014. August AOD in 2011 is 1.18 , much higher than in $2012(0.75)$ and $2013(0.63)$ as obtained from the MODIS retrievals. As a result, the AOD in August shown in Fig. 1 is unusually high.

The aerosol AEs also have substantial seasonal variations, especially for the absorbing aerosols, as illustrated in Fig. 2. The seasonal variation of the fine-aerosol AE is highly consistent with the coarse one for the absorbing aerosols, while the opposite is found for the scattering aerosols. Nevertheless, all AEs in the summer are close to 0, possibly due to the effects of high RH (Zhuang et al., 2014a). The whole mode $\mathrm{AE}$ of each aerosol type is determined by the both variations in the AEs in each mode and the fine-mode fraction. Therefore, the smallest AEs appear in the summer ( 0.74 in July) for the total absorbing aerosols but appear in the spring $(0.94$ in March) for the total scattering aerosols. Similarly, the to- 


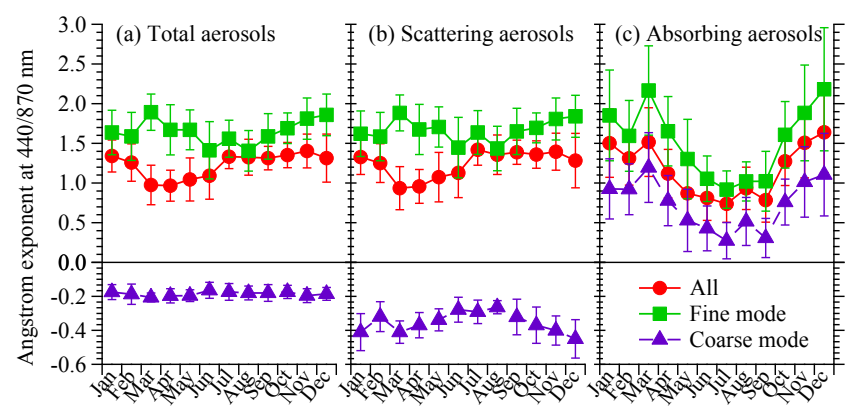

Figure 2. Monthly variations in the total (a), scattering (b) and absorbing aerosol (c) Ångström exponents (AE) at 440/870 nm for the all, fine and coarse modes in the urban area of Nanjing.

tal aerosol AE is determined by both the variations of each aerosol type's AE and the ratio of the scattering (or absorbing) aerosols to the total. The seasonality of the total aerosol AEs is more consistent with that of the scattering aerosols. The figure also indicates that the scattering aerosols are much larger than the absorbing aerosols, especially those in the coarse mode. Further comparisons indicate that the seasonal variations in the columnar SAE and AAE are consistent with their surface ones (Zhuang et al., 2017) at the site.

In addition to AOD and AE, the monthly variations in the aerosol SSAs and refractive indices are investigated as shown in Fig. 3. SSA is affected by both scattering and absorbing aerosols, as well as their relative contributions. The fine particles have much stronger scatterings than the coarse aerosols. Their SSAs have relatively weaker seasonality. Overall, both FSSA and CSSA are relatively smaller in the warmer seasons, although they were considerably large in August 2011. The total aerosol SSA is somewhere between the FSSA and CSSA and depends on the ratios of FAOD to AOD. Thus, these SSAs have different seasonal variations from the FSSA or CSSA. SSA is also rather small in spring due to the largest contribution of coarse aerosols occurring in this season. The aerosol refractive indices also show considerable seasonality. The real part is large in the spring but small in the summer, which is similar to what was observed in Taihu Lake in the central YRD (Yu et al., 2011). The imaginary parts show relatively weaker seasonal variations than the real parts.

To provide a more quantitative knowledge, Table 2 summarizes the above-mentioned seasonal means with the corresponding standard deviations for all the aerosol optical properties. It more obviously reflects the different variations in the optical properties among different aerosol categories. For example, CAOD, CSAOD and CAAOD account for the majority of the AOD, SAOD and AAOD in the spring, with ratios of 30.1, 27.9 and 58.1\%, respectively. FAOD, FSAOD and FAAOD account for the majority of the AOD, SAOD and AAOD in the summer, with ratios of $90.5,91.2$ and $70.2 \%$. Comparisons indicate that the seasonal variations in the optical properties are highly spatially inhomogeneous within the

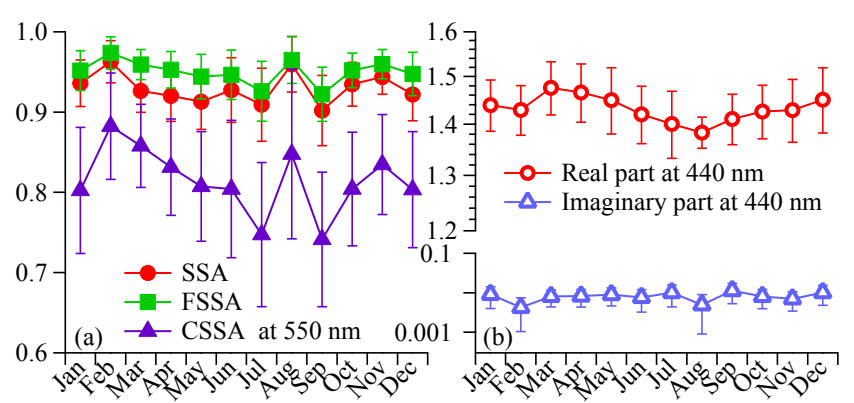

Figure 3. Monthly variations in the all, fine and coarse-mode aerosol single scattering albedo (SSA) at $550 \mathrm{~nm}$ (a) and the aerosol refractive indices at $440 \mathrm{~nm}$ (b) in the urban area of Nanjing.

YRD. As indicated by Che et al. (2015a) and Qi et al. (2016), the largest AOD was found in the spring, while the lowest one appeared in the summer in urHZ, another city on the eastern coast of the YRD. In Taihu Lake, a rural site in the central YRD, the lowest AOD appeared in the winter (Pan et al., 2010; Yu et al., 2011). Additionally, the aerosols absorb the most in the winter in the central regions of the YRD (Taihu Lake and urHZ), and their SSAs are as small as 0.88 (Yu et al., 2011; Qi et al., 2016). The aerosols in the western YRD (urNJ) are more scattering than those in other areas. Nevertheless, AE variations are more consistent with each other between these sites, being smallest in the spring and largest in the autumn.

\subsubsection{Frequencies of the aerosol optical properties}

All AODs and SSAs follow a near log-normal pattern, and almost all the AEs and refractive indices follow a unimodal pattern (Fig. 4). The ranges around their means are dominant, accounting for at least $60 \%$ of the total data samples during the entire study period. Similarly to the temporal variations, the frequency distributions of the total aerosols (not shown) are also highly similar to those of the scattering aerosols in both the fine and coarse modes. The frequencies of the absorbing aerosol AEs differ from those of the scattering aerosol AEs. The occurrences of smaller CAAE (or large FAAE, AAE) values are also relatively high. Due to different absorbed fractions among coarse, fine and total aerosols, the curve of CSSA (FSSA) has a leftward (rightward) shift compared with that of SSA, peaking around 0.84 (0.97). The fine-aerosol SSAs were concentrated in a narrower range $(\sim 0.1)$ than the CSSAs were $(\sim 0.3)$. For the refractive index, the frequencies peak around 1.42 and 0.008 for the real and imaginary parts in urNJ during the study period. The frequency patterns of the aerosol optical properties also have substantial seasonality (not shown here). Overall, the curves shift leftward in low-value seasons and rightward in high-value seasons. In the summer, the AOD curves might even have two peaks for the scattering or total aerosols, 
Table 2. Seasonal mean \pm SD of the columnar aerosol optical properties in the urban area of Nanjing.

\begin{tabular}{lrrrr}
\hline Factors & MAM & JJA & SON & DJF \\
\hline $550 \mathrm{~nm}$ AOD & $0.6788 \pm 0.2919$ & $0.7508 \pm 0.3749$ & $0.5866 \pm 0.2447$ & $0.6560 \pm 0.2976$ \\
$550 \mathrm{~nm}$ FAOD & $0.4739 \pm 0.2613$ & $0.6798 \pm 0.3793$ & $0.5149 \pm 0.2462$ & $0.5687 \pm 0.2978$ \\
$550 \mathrm{~nm}$ CAOD & $0.2048 \pm 0.1356$ & $0.0710 \pm 0.0599$ & $0.0717 \pm 0.0346$ & $0.0873 \pm 0.0685$ \\
$550 \mathrm{~nm}$ SAOD & $0.6284 \pm 0.2835$ & $0.7031 \pm 0.3728$ & $0.5495 \pm 0.2342$ & $0.6157 \pm 0.2829$ \\
$550 \mathrm{~nm}$ FSAOD & $0.4529 \pm 0.2552$ & $0.6463 \pm 0.3760$ & $0.4901 \pm 0.2366$ & $0.5428 \pm 0.2846$ \\
$550 \mathrm{~nm}$ CSAOD & $0.1756 \pm 0.1225$ & $0.0568 \pm 0.0497$ & $0.0593 \pm 0.0315$ & $0.0728 \pm 0.0601$ \\
$550 \mathrm{~nm}$ AAOD & $0.0503 \pm 0.0208$ & $0.0477 \pm 0.0307$ & $0.0372 \pm 0.0200$ & $0.0403 \pm 0.0271$ \\
$550 \mathrm{~nm}$ FAAOD & $0.0211 \pm 0.0125$ & $0.0335 \pm 0.0212$ & $0.0248 \pm 0.0157$ & $0.0259 \pm 0.0211$ \\
$550 \mathrm{~nm}$ CAAOD & $0.0292 \pm 0.0165$ & $0.0142 \pm 0.0137$ & $0.0124 \pm 0.0066$ & $0.0144 \pm 0.0111$ \\
$440 / 870 \mathrm{~nm}$ AE & $0.9915 \pm 0.2385$ & $1.2174 \pm 0.2639$ & $1.3744 \pm 0.1907$ & $1.3134 \pm 0.2461$ \\
$440 / 870 \mathrm{~nm}$ FAE & $1.7474 \pm 0.2896$ & $1.4701 \pm 0.3075$ & $1.7408 \pm 0.2582$ & $1.6935 \pm 0.3019$ \\
$440 / 870 \mathrm{~nm}$ CAE & $-0.1998 \pm 0.0352$ & $-0.1699 \pm 0.0471$ & $-0.1862 \pm 0.0424$ & $-0.1807 \pm 0.0464$ \\
$440 / 870 \mathrm{~nm}$ SAE & $0.9812 \pm 0.2687$ & $1.2733 \pm 0.2950$ & $1.3824 \pm 0.2043$ & $1.2956 \pm 0.2697$ \\
$440 / 870 \mathrm{~nm}$ SFAE & $1.7555 \pm 0.2862$ & $1.5218 \pm 0.3397$ & $1.7492 \pm 0.2545$ & $1.6809 \pm 0.3039$ \\
$440 / 870 \mathrm{~nm}$ SCAE & $-0.3752 \pm 0.0743$ & $-0.2815 \pm 0.0678$ & $-0.3797 \pm 0.0991$ & $-0.4016 \pm 0.1162$ \\
$440 / 870 \mathrm{~nm}$ AAE & $1.1885 \pm 0.4500$ & $0.7971 \pm 0.2657$ & $1.3290 \pm 0.4533$ & $1.5007 \pm 0.4520$ \\
$440 / 870 \mathrm{~nm}$ FAAE & $1.7352 \pm 0.6059$ & $0.9943 \pm 0.2672$ & $1.6715 \pm 0.5970$ & $1.8947 \pm 0.6545$ \\
$440 / 870 \mathrm{~nm}$ CAAE & $0.8542 \pm 0.4665$ & $0.3771 \pm 0.2753$ & $0.8312 \pm 0.4479$ & $0.9798 \pm 0.4235$ \\
$550 \mathrm{~nm}$ SSA & $0.9204 \pm 0.0313$ & $0.9241 \pm 0.0422$ & $0.9348 \pm 0.0331$ & $0.9378 \pm 0.0331$ \\
$550 \mathrm{~nm}$ FSSA & $0.9527 \pm 0.0237$ & $0.9405 \pm 0.0356$ & $0.9518 \pm 0.0253$ & $0.9555 \pm 0.0265$ \\
$550 \mathrm{~nm}$ CSSA & $0.8340 \pm 0.0628$ & $0.7868 \pm 0.0953$ & $0.8115 \pm 0.0752$ & $0.8211 \pm 0.0810$ \\
$440 \mathrm{~nm}$ real part & $1.4647 \pm 0.0628$ & $1.4075 \pm 0.0609$ & $1.4252 \pm 0.0602$ & $1.4404 \pm 0.0582$ \\
$440 \mathrm{~nm}$ imaginary part & $0.0084 \pm 0.0040$ & $0.0083 \pm 0.0052$ & $0.0080 \pm 0.0044$ & $0.0083 \pm 0.0053$ \\
\hline
\end{tabular}

which are similar to the observations at Taihu Lake (Yu et al., 2011).

\subsubsection{Comparisons with MODIS AOD, AE and surface aerosols}

The AOD and AE observed by CE-318, to degrees, are well correlated with those from MODIS in terms of their seasonal variations and magnitudes (Fig. 5). The linear correlation coefficients are 0.71 and 0.67 between the monthly mean CE318 and MODIS AODs and between the monthly mean CE318 and MODIS AEs, respectively. The AOD from MODIS is greater $(\sim 1.2$ times) than that from CE-318, with an average value of 0.80 during the study period. The slope of the linear fitting is 1.12 for AOD in urNJ, similar to that in central China (slope $=1.16$, Dong et al., 2013). The mean AE at $412 / 470 \mathrm{~nm}$ from MODIS is approximately 1.42 . The standard deviations of the AOD and AE values are much larger for CE-318 than for MODIS, possibly due to the higher temporal resolution of the CE-318 observations.

The columnar AAOD and AAE values from CE-318 are less related to the surface aerosol absorption coefficient (AAC) and AAE from AE-31 (Fig. 6). Because surface aerosols are mainly affected by local and regional emissions, and their loadings are highly related to the degrees of boundary layer development (Zhuang et al., 2014b, 2015). The columnar AAODs could be further affected by emissions and transports in the upper atmosphere. The surface AAE is con- centrated in a narrower range and is larger (1.6) than that from CE-318. The linear correlation coefficients between the AAOD and AAC and between the columnar and surface AAEs are 0.39 and 0.41 , respectively, which are slightly worse than those between FAAOD and AAC (0.46) and between the columnar FAAE and surface AAE (0.47).

\subsubsection{Brief discussions}

Results here allow us to better understand the characteristics of the aerosols in the YRD and they might be also useful for improving aerosol model performances and their radiative effects in the YRD or eastern China as referred to in the Introduction.

Most studies of the aerosol optical properties in China mainly focus on the AOD and AE of the short-term total aerosols (i.e. episodes, Che et al., 2013, 2015b; Zheng et al., 2016), although studies on the annual (Yu et al., 2011) and decadal (Che et al., 2015a)-scale aerosols have been also carried out in recent years based on CE-318 measurements. Results here show that the mean AOD in urNJ is greater than in northern China and the PRD is smaller than in the coastal cities of the YRD. The AE is larger in urNJ than in northern and central China. Che et al. (2015a) further suggested that those aerosols in urban areas likely had larger AODs and AEs than those in mountain and desert areas. It is the same in urNJ. Qi et al. (2016) showed that the aerosol SSAs at $440 \mathrm{~nm}$ in $\mathrm{urHZ}$ are approximately $0.90,0.92$ and 0.70 for the 


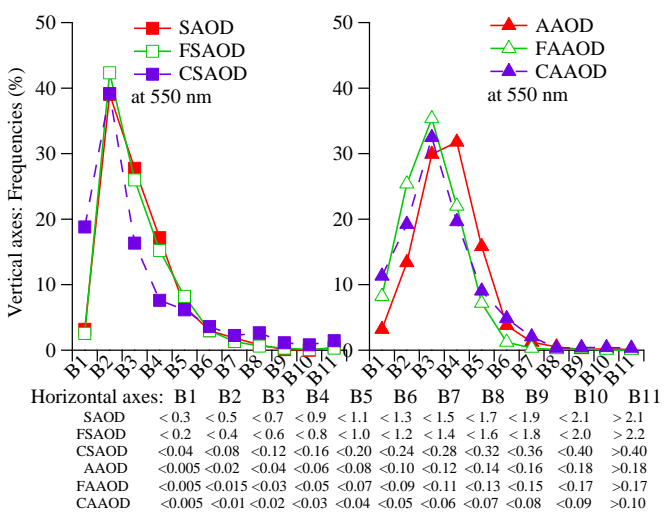

(a)

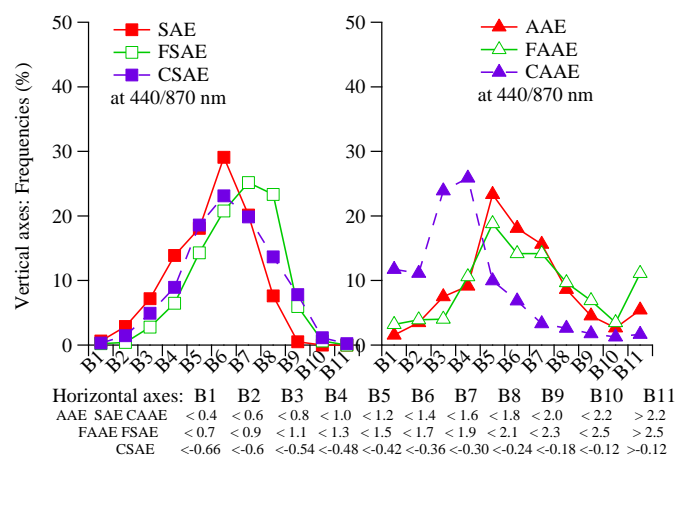

(b)

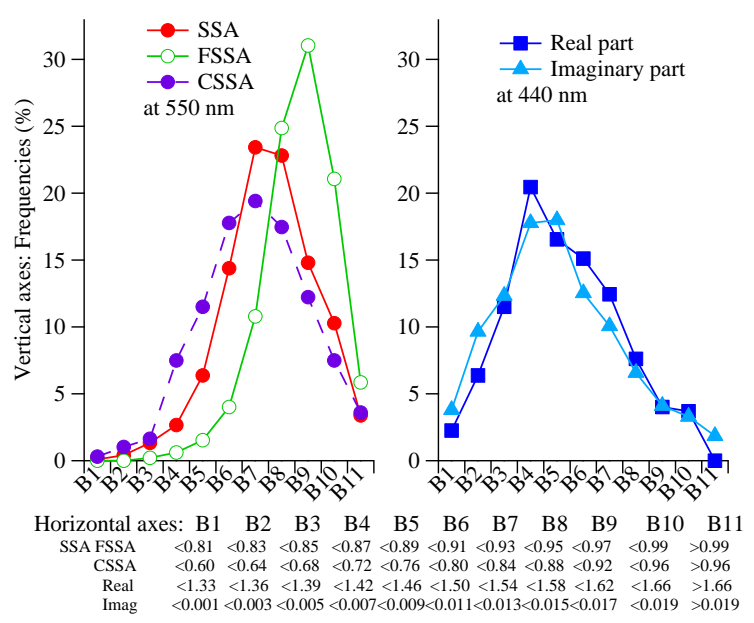

(c)

Figure 4. Frequency distributions of the size-dependent AODs at $550 \mathrm{~nm}$ (a), AEs at $440 / 870 \mathrm{~nm}$ (b), SSAs at $550 \mathrm{~nm}(\mathbf{c})$ as well as the real and imaginary parts at $440 \mathrm{~nm}$ (c) in the urban area of Nanjing.

total, fine and coarse aerosols, also implying that the coarse aerosols absorb more than the fine ones. Our measurements show similar results. However, the aerosols in urNJ scatter more than those in urHZ in both the fine and coarse modes, also revealing inhomogeneous distributions of the aerosol compositions in the YRD. This study further augments the current observations of the aerosol optical properties in the YRD compared with previous studies.

\subsection{Physical properties of the aerosols}

In addition to the optical properties, the aerosol physical properties were retrieved, including the volume size distributions, mode-dependent sizes (radius) and volume concentrations. Figure 7 shows the volume size distributions of the aerosols in different seasons (Fig. 7a) and at different AOD (or polluted) levels (Fig. 7b) in urNJ. It shows that the aerosols in urNJ have a typical bimodal structure in their vol- ume size distributions in all seasons, presenting two-mode log-normal distributions in both the fine (radius $<0.6 \mu \mathrm{m}$ ) and coarse modes (radius $>0.6 \mu \mathrm{m}$ ). Their annual peaks appear at radii of $0.148 \mu \mathrm{m}$ for the fine mode and $2.94 \mu \mathrm{m}$ for the coarse mode. The aerosol volume size distributions also have substantial seasonality. Dust episodes lead to the peak values in the spring being much smaller in the fine mode than in the coarse mode, which is the opposite trend to other seasons (especially in the summer). Therefore, the mean radius of the aerosols increases significantly in the spring due to the high proportion of coarse particles, leading to a smaller $\mathrm{AE}$, as discussed in the previous sections. In the summer, the curve has a rightward shift, showing a larger aerosol size in both the fine and coarse modes due to the high hygroscopic growth efficiency. The fine particles are dominant in the summer and result in large AE values, in contrast to the patterns in the spring. The aerosol volume size distribution varies with different AOD values (Fig. 7b) in urNJ. Overall, 

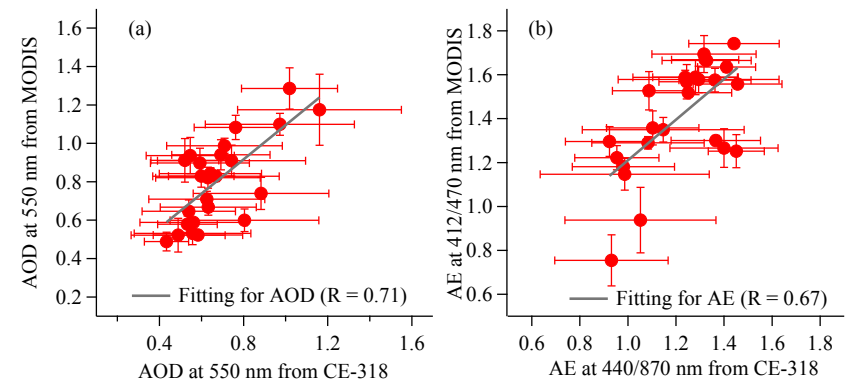

Figure 5. Comparisons between CE-318 and MODIS-based AOD at $550 \mathrm{~nm}$ and between $\mathrm{AE}$ at $440 / 870 \mathrm{~nm}$ for CE-318 and at $412 / 470 \mathrm{~nm}$ for MODIS in Nanjing.

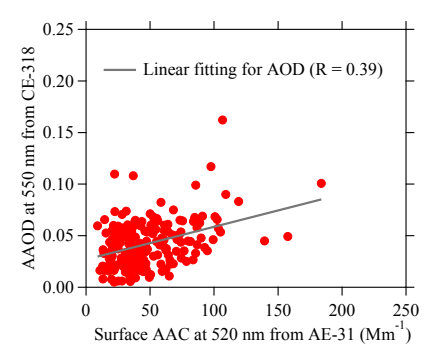

(a)

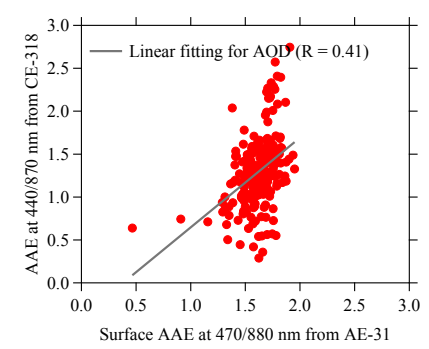

(b)
Figure 6. Comparisons between the absorbing aerosol optical depth (AAOD) at $550 \mathrm{~nm}$ from CE-318 and surface absorption coefficient (AAC) at $520 \mathrm{~nm}$ from AE-31 (a) and between the column AAE at $440 / 870 \mathrm{~nm}$ from CE-318 and surface AAE at 470/880 nm from AE-31 (b) in urban Nanjing.

the peak value has a substantial rightward shift with increasing AOD for fine aerosols but a slightly leftward shift for coarse aerosols, implying that the growth of the fine aerosols is advantageous to enhance the aerosol radiative effect. In urNJ, both fine and coarse particles have approximately the same levels when AOD is below $\sim 0.8$. In addition, the fine aerosols begin to dominate more when AOD $>0.8$. The results here are mostly consistent with the ones from $\mathrm{Yu}$ et al. (2011), Qi et al. (2016) and Zheng et al. (2016). However, the figure here further indicates that both fine and coarse particles themselves might cause very serious haze pollution in YRD, showing considerably high peak values in both fine and coarse modes, which has not been observed in previous publications. The aerosol size distributions here are also very useful for optimizing numerical models.

To further investigate the physical features, the seasonal variations in the aerosol effective and mean radius and the volume concentrations in urNJ are presented in Fig. 8. The mean effective radius, which is generally smaller than the mean one in all modes, is approximately $0.34,0.16$ and $2.18 \mu \mathrm{m}$ for the total, fine and coarse aerosols during the study period. The seasonal variations in the radii have a strong anti-correlation to that of the AEs (Fig. 2). Both the fine- and coarse-aerosol radii are larger in the summer than in the other seasons while the total aerosol radius is much larger in the spring. Unlike the radius, the seasonal variations in the volume concentrations of the fine and coarse aerosols are different, peaking in the spring for coarse aerosols and in the summer for fine aerosols. Although both the fine and coarse aerosols have the same annual volume levels in urNJ, their contributions to the total aerosol volumes vary significantly with season. The coarse aerosols lead directly to the largest total aerosol volume peaking in the spring.

\subsection{Aerosol classification based on optical properties}

The aerosol clusters, to a certain degree, can be identified based on the relationships between SSAs at 491 and AEs at $491 / 870 \mathrm{~nm}$, between the real refractive index (RRI) at 670 and the AE at $491 / 870 \mathrm{~nm}$ and between the SSA differences $\left(\mathrm{dSSA}=\mathrm{SSA}_{870 \mathrm{~nm}}-\mathrm{SSA}_{491 \mathrm{~nm}}\right)$ and AE at $491 / 870 \mathrm{~nm}$, as presented by Russell et al. (2014). They proposed a Mahalanobis classification based on a priori information for each type of aerosol source (e.g. dust, urban, biomass aerosols). Different aerosols would then be mostly concentrated within the corresponding ellipses of a two-dimensional scatter plot of SSA versus AE (or RRI versus AE, or dSSA versus AE). Based on their classifications, aerosols from pure dust, polluted dust, biomass burning, industrial urban, developing urban and marine sources (Fig. 8 in Russell et al., 2014) can be identified. For example, the polluted dust aerosols are mostly within the ellipses with smaller AE (near 1.0) values, relatively small SSA levels (0.85 to 0.95 ), and much larger real refractive indices (1.45 to 1.55 ) and SSA differences ( 0 to 0.05 ) than those present for other aerosols. The aerosols from a developing urban area generally have smaller sizes than polluted dust (AE ranging from 1 to 1.6), but they have larger SSA (0.9 to 1.0$)$ values, smaller real refractive indices (1.4 to 1.5 ) and smaller SSA differences (approximately 0). More classifications can be found in Russell et al. (2014). Based on their classification standards, the aerosols in urNJ could be basically identified as clusters of polluted dust, developing urban and industrial urban during the sampling period, as shown in Fig. 9, which further supports the analysis in Section 3. Although urNJ is only approximately $300-400 \mathrm{~km}$ away from the East China Sea, few marine or sea salt aerosol components are observed, as illustrated in Fig. 9. Unfortunately, the observations missed a biomass burning event in June 2012 (Zhuang et al., 2014b, 2015) because the instrument was under maintenance. Otherwise, the figure would be more comprehensive. An analysis here might help us understand the aerosol sources, transformations, transports and radiative effects in the YRD. In addition, this information indicates that the Mahalanobis classification is a very useful approach for classifying aerosol into types, especially in cases of data shortages or insufficient methods. However, this method still has a limitation. The classified ellipses have some overlaps among different aerosols clusters. In overlap regions, classifying the aerosols into types is a challenge. 


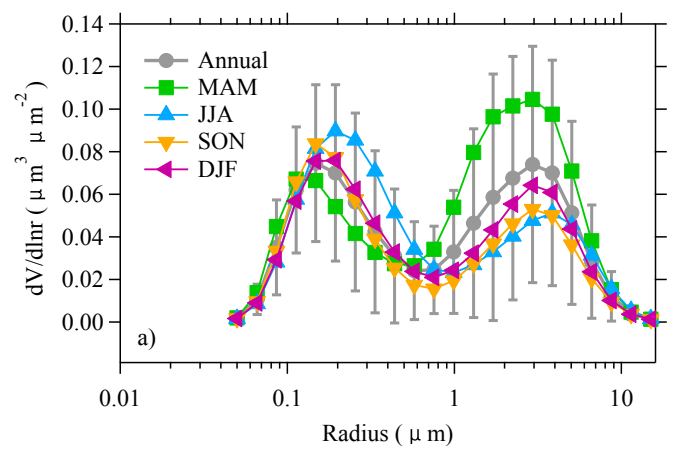

(a)

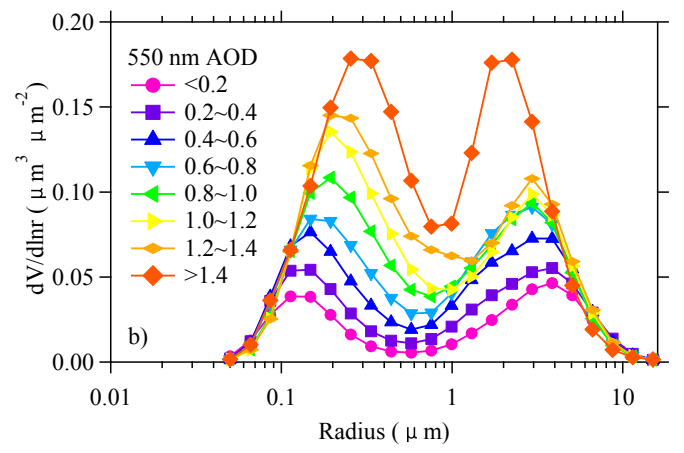

(b)

Figure 7. The averaged aerosol volume size $\left(\mu \mathrm{m}^{3} \mu \mathrm{m}^{-2}\right)$ distributions in different seasons (a) and in different AOD levels (b) in urban Nanjing.

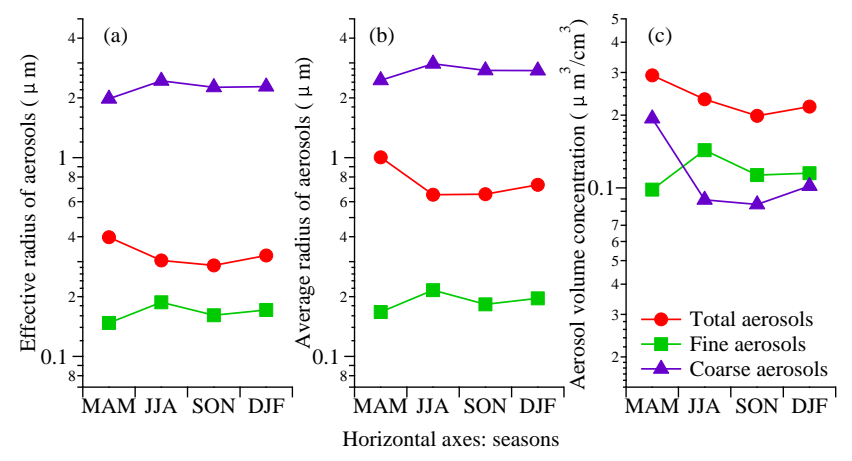

Figure 8. Seasonal variations in the effective (a) and mean (b) radius of aerosols as well as the aerosol volume concentrations (c) in the all, fine and coarse modes in urban Nanjing.

For example, it is not easy to distinguish between polluted dust aerosols with large AE values and urban aerosols with smaller AE. Therefore, if there are two kinds of aerosols with nearly identical coordinates, further information is needed, or a more effective approach should be taken into account.

In addition to types, the aerosol mixtures/compositions can be identified based on SSA and AAOD. Generally, dust aerosols have strong absorption in the ultraviolet (UV) band but become non-absorbing in the visible band, leading to SSAs increasing monotonically with wavelength. For biomass burning aerosols, the SSAs decrease monotonically with wavelength. Non-monotonic variations in SSA with changes in wavelength might be due to aerosol mixtures dominated by another type of aerosol, as indicated by $\mathrm{Li}$ et al. (2015a). They proposed two curvature parameters to provide additional information on the aerosol compositions: the second derivative of the second-order polynomial fit of the SSA and wavelength and the fit of the AAOD and wavelength, as shown in Eqs. (4) and (5).

$$
\ln \left(\mathrm{SSA}_{\lambda}\right)=\beta_{2} \ln (\lambda)^{2}+\beta_{1} \ln (\lambda)+\beta_{0}
$$

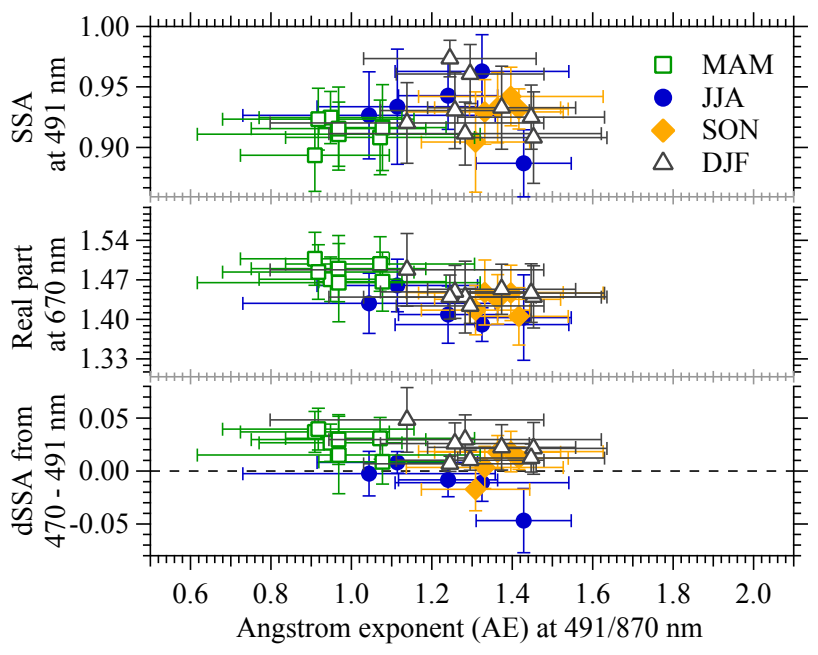

Figure 9. Relationships between the monthly mean values of $491 \mathrm{~nm}$ SSA and total Ångström exponent (AE) at 491/870 nm (a), between the monthly mean values of the real refractive index at 670 and $\mathrm{AE}$ at $491 / 870 \mathrm{~nm}$ (b) and between the monthly mean values of the SSA difference (870-491 nm) and AE at 491/870 nm (c).

$\ln \left(\mathrm{AAOD}_{\lambda}\right)=\alpha_{2} \ln (\lambda)^{2}+\alpha_{1} \ln (\lambda)+\alpha_{0}$,

where $-\beta_{2}$ and $\alpha_{2}$ are the SSA curvature and AADO curvature. Detailed descriptions were presented by $\mathrm{Li}$ et al. (2015a). Based on these parameters, the aerosols can be identified as dust dominated, BC (including biomass burning and urban/industrial aerosols) dominated and other mixed (peak) type aerosols because the curvature probability (or frequency) distributions are different for the different aerosol mixtures. As indicated in Li et al. (2015a), the SSA or AAOD curvature is mostly concentrated at approximately 0 for the BC-dominated aerosol mixture, which is much smaller than that of the dust-dominated aerosol mixtures ( 0.1 for SSA curvature and 0.5-1 for AAOD curvature) over East Asia. Based on their method, the curvatures of SSA and AAOD are calcu- 


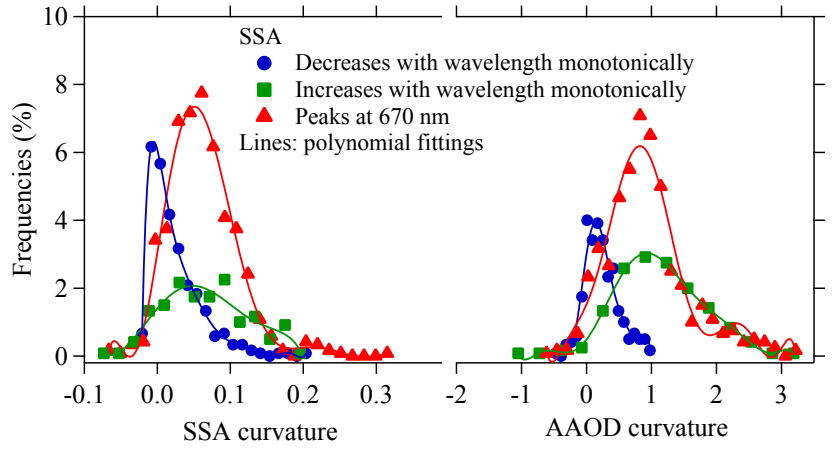

Figure 10. Distribution of the SSA and AAOD curvatures in the urban area of Nanjing under different spectral SSA conditions, including monotonically decreasing, increasing SSA spectra and peaked SSA spectra.

lated and then divided into three categories according to the monotonicity of the SSA. The results show that there are approximately 15.0, 27.5 and $42.3 \%$ occurrences of monotonically increasing, decreasing and $670 \mathrm{~nm}$ peaking SSA spectra, respectively, in urNJ. In addition, their probability (or frequency) distributions are plotted in Fig. 10. The figure indicates that the SSA and AAOD curvature patterns are highly consistent with those in $\mathrm{Li}$ et al. (2015a) for the monotonic categories, which implies that the $\sim 15$ and $\sim 27 \%$ samples with monotonically increasing and decreasing SSA spectra are the dust-dominated and $\mathrm{BC}$-dominated mixing aerosols, respectively, in urNJ during the observed period. For example, a very strong dust storm from north-western China and Mongolia on 1 May 2011 (Li et al., 2015a) directly yielded mean SSA and AAOD curvatures of 0.12 and 1.11, which are close to the values (0.11 and 1.24) of the pure dust aerosols (Li et al., 2015a). For the rest of the categories with nonmonotonic SSA spectra, the SSA curvatures are mostly concentrated from 0.3 to 0.8 , implying that the dust component might not exceed $10 \%$, while the scattering species (organic carbon not included) accounted for at least $30 \%$ of the mixing particles in the western YRD according to the sensitivity results from $\mathrm{Li}$ et al. (2015a). Additional data are needed to derive further information. However, these results might help us gain a better understanding of the mixings of aerosols in the urban areas of the YRD. Similarly to Russell et al. (2014), S. Li et al. (2015) provided an effective approach for classifying the aerosol compositions based on a single data set (such as the CE-318 retrievals).

\subsection{The direct radiative forcing of the aerosols}

Based on the above-mentioned wavelength-dependent optical properties combined with the observed surface albedo and aerosol profiles, the clear-sky size-dependent aerosol DRF of the fine and coarse components at both the TOA and the surface in urNJ are investigated using the radiation transfer model TUV (Madronich, 1993). Due to a lack of SSA ob-

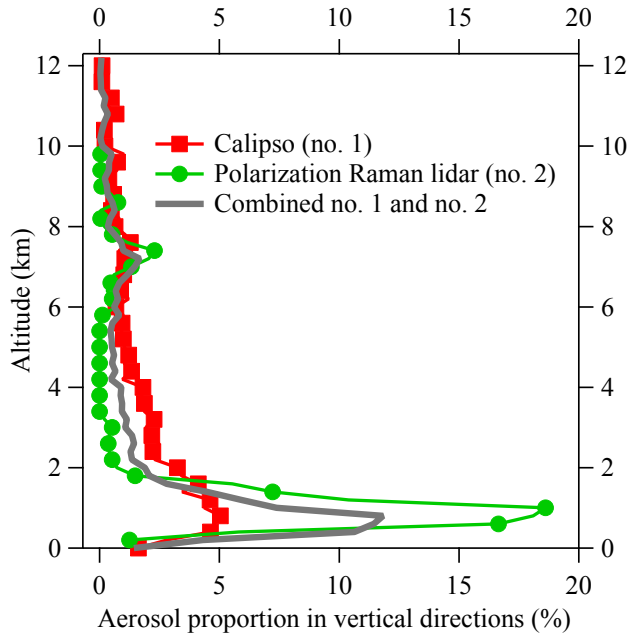

Figure 11. The aerosol vertical proportions (\%) from CALIPSO and the polarization Raman lidar and their average in Nanjing.

servations of each aerosol component, the scattering aerosol DRF is estimated based on a given SSA value (0.9999, equal to that of sulfate or nitrate aerosol) in a reference ( $\mathrm{Li}$ et al., 2015b). As indicated in the last section, the absorbing aerosols in urNJ are always in a mixed state. Therefore, the absorbing aerosol DRF cannot be estimated directly using the BC SSA. Here, this value is derived from the difference between the total and scattering aerosol DRFs, which might be more representative. For comparison, the aerosol DRF is also calculated based on the AAODs, AAEs and BC SSA ( $\mathrm{Li}$ et al., 2015b).

Observational aerosol profiles, which have not have been used in previous investigations (e.g. Zhuang et al., 2014a), might be important to the DRF estimations. Figure 11 shows the mean vertical aerosol profiles observed by CALIPSO (annual scale data) and the PRL (seasonal scale data) in Nanjing. For further comparisons, all the profiles in the figure were standardized to percentages (\%). The figure suggests that the ground and satellite-based aerosol profiles are substantially different. The CALIPSO profile is more homogeneous than the PRL one: they account for approximately 61 and $88 \%$, respectively, below $4 \mathrm{~km}$. Due to the lack of the long-term measurements of PRL and the different products of the different observational platforms, both the CALIPSO and PRL profiles are used here. Additionally, a combined profile (grey line) of the averaged CALIPSO and PRL values is included and indicates that aerosols account for approximately $75 \%$ of the total below $4 \mathrm{~km}$ and approximately $60 \%$ in the boundary layer for the combined profile, which is somewhat similar to the default profile of TUV (Palancar and Toselli, 2004). All these four profiles were used when estimating the aerosol DRFs. 


\subsubsection{The aerosol direct radiative forcing in clear-sky conditions}

Hereinafter, DRFs, unless otherwise specified, represent the averaged values from CALIPSO, PRL and a combined profile-based forcing in clear-sky conditions. Figure 12 shows the seasonal variations in the size-dependent daytime TOA and surface DRFs of the total, scattering and absorbing aerosols in urNJ. The aerosol DRFs are highly dependent on the aerosol optical properties and compositions. Overall, the fine aerosols contribute considerably more to the total aerosol DRFs, especially for scattering aerosols. The coarse-aerosol DRF accounts for only $13.3 \%$ for the scattering aerosols, while this fraction is $>33.7 \%$ for the absorbing aerosols at both the TOA and surface in urNJ. Negative scattering aerosol DRFs could be significantly offset at the TOA and could be further strengthened at the surface by absorbing aerosols. Therefore, the total coarse-aerosol DRF at the TOA is very weak due to a much smaller CSSA and subsequently accounts for a much smaller contribution to the total aerosol DRF than the fine aerosols do. Both the scattering and absorbing aerosol DRFs have similar seasonality to their AODs, and the scattering aerosol DRFs have the same seasonality as the absorbing ones within the same mode. In addition to AODs, the surface albedo and solar zenith angle have a strong influence on the variations in the aerosol DRFs. As implied by Zhuang et al. (2014a), a brighter surface would yield a weaker negative DRF and a stronger positive DRF, assuming a fixed AOD. The seasonal mean surface albedo averaged from four wavelengths $(440,670,870$ and $1020 \mathrm{~nm})$ is approximately $0.145,0.170,0.129$ and 0.137 in the spring, summer, autumn and winter, respectively. As a result, the scattering and fine absorbing aerosol DRFs are also strong in the winter and spring. Unlike those of the single aerosol types, the variations in the total aerosol DRFs are co-affected by those of both the scattering and absorbing aerosols. Thus, the strongest TOA DRF of the total fine aerosols appears in the winter instead of the summer, and the total coarse-aerosol DRFs are positive at the TOA in the summer. For all modes, the seasonal variations of the total aerosol DRFs at the TOA are more consistent with those of the fine mode. In contrast to the TOA DRFs of the total aerosols, the surface DRFs are much more consistent with those of the corresponding AODs.

For further comparisons (Fig. 13), the absorbing aerosol DRFs based on the observed AAOD, AAE and fresh BC SSA (Li et al., 2015b) are also used. Although the absorbing aerosol DRFs are estimated in different ways, they are highly correlated at both the TOA and surface, as shown in the figure. Apparently, the DRFs from the second method are much weaker than those from the first calculation, possibly due to the absorbing aerosols in urNJ being in a constantly mixed state, as shown by the analysis in the previous section and as indicated by Zhuang et al. (2015). Jacobson (2000) suggested that the aged (mixed) absorbing aerosols have a

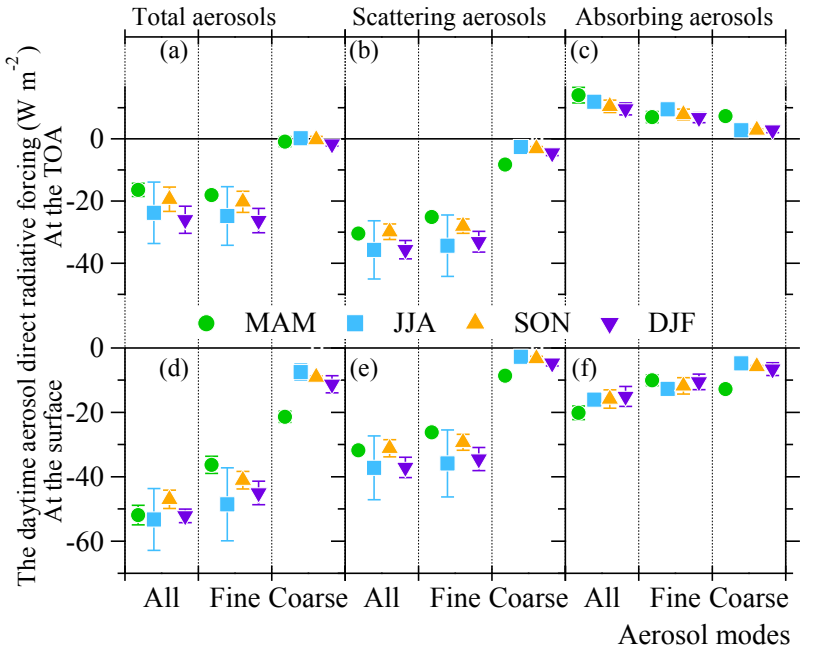

Figure 12. Seasonal variations of the clear-sky aerosol direct radiative forcing (DRF, $\mathrm{W} \mathrm{m}^{-2}$ ) at both TOA (a-c) and the surface (d-f). The DRFs of the total (a, d), scattering $(\mathbf{b}, \mathbf{e})$ and absorbing $(\mathbf{c}, \mathbf{f})$ aerosols in the all, fine and coarse modes are all investigated in urban Nanjing.

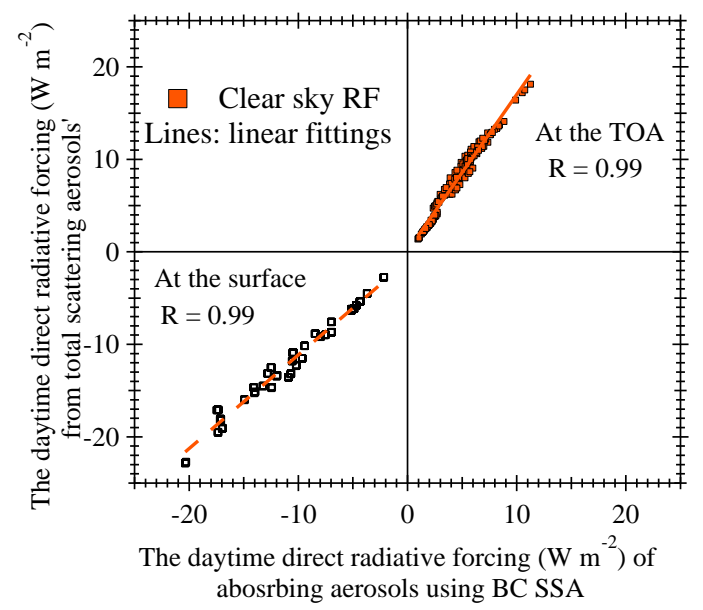

Figure 13. Comparisons in the absorbing aerosol DRFs $\left(\mathrm{W} \mathrm{m}^{-2}\right)$ between from BC SSA and from the total aerosol DRF minus the scattering one.

much stronger ability to absorb solar radiation, by a factor of 2. Zhuang et al. (2013a, b) stated that the simulated regional mean TOA DRF of the mixed BC $\left(+1.56 \mathrm{~W} \mathrm{~m}^{-2}\right)$ over East Asia is approximately 1.9 times that of the unmixed BC. The ratio is approximately 1.73 in this study, implying that the absorbing aerosol DRF from the first method is reasonable. The comparison here further proves the importance of the mixing states in estimating the absorbing aerosol radiative effects.

Table 3 lists the annual mean size-dependent DRFs of the total, scattering and absorbing aerosols at both the TOA and the surface in urNJ. The DRFs at the surface are all stronger than those at the TOA. The mean DRFs are -10.69 , 
Table 3. The annual mean aerosol direct radiative forcing $\left(\mathrm{W} \mathrm{m}^{-2}\right)$ in the urban area of Nanjing.

\begin{tabular}{lrr}
\hline & \multicolumn{2}{c}{ Clear sky } \\
\cline { 2 - 3 } Species & TOA & Surface \\
\hline TA & $-10.69 \pm 3.37$ & $-25.54 \pm 2.83$ \\
FA & $-11.17 \pm 3.09$ & $-21.37 \pm 2.78$ \\
CA & $-0.33 \pm 0.60$ & $-6.15 \pm 2.90$ \\
SA & $-16.45 \pm 2.81$ & $-17.17 \pm 2.96$ \\
FSA & $-15.08 \pm 3.18$ & $-15.74 \pm 3.35$ \\
CSA & $-2.31 \pm 1.18$ & $-2.42 \pm 1.24$ \\
AA & $5.76 \pm 1.27$ & $-8.38 \pm 1.56$ \\
FAA & $3.91 \pm 0.95$ & $-5.63 \pm 1.16$ \\
CAA & $1.99 \pm 1.07$ & $-3.73 \pm 1.71$ \\
\hline
\end{tabular}

TA: total aerosols. FA: fine aerosols. CA: coarse aerosols. SA: all scattering aerosols. FSA: scattering aerosols in fine mode. CSA: scattering aerosols in coarse mode. AA: all absorbing aerosol forcing. FAA: fine absorbing aerosol forcing. CAA: coarse absorbing aerosol forcing.

$-16.45,5.76 \mathrm{~W} \mathrm{~m}^{-2}$ at the TOA and $-25.54,-21.37$ and $-8.38 \mathrm{~W} \mathrm{~m}^{-2}$ at the surface for the TA, SA and AA. The fine-mode TOA DRFs are nearly an order of magnitude stronger than those of the coarse mode for the total and scattering aerosols. The DRFs of the fine absorbing aerosols have the same order of magnitude but are stronger than those of the coarse absorbing aerosols. Note that the total DRFs in the table are not exactly the sum of the contributions from the fine and coarse ones, because the coarse-aerosol affection on the solar radiation is excluded when calculating the fine aerosol DRF separately, and vice versa.

Various studies of aerosol DRFs have been carried out based on observations or numerical models. Overall, the DRFs of urban aerosols are much stronger than those on regional or global scales. Forster et al. (2007) summarized the global mean clear-sky DRFs of the total observational aerosols as $-5.4 \mathrm{~W} \mathrm{~m}^{-2}$. Zhuang et al. (2013a, b) indicated that simulated clear-sky DRFs are $-4.97 \mathrm{~W} \mathrm{~m}^{-2}$ for total aerosols and $+1.2 \mathrm{~W} \mathrm{~m}^{-2}$ for BC over East Asia. On a subregional or urban scale, the observation-based analysis showed that the total aerosol DRFs always exceeded $10^{1} \mathrm{~W} \mathrm{~m}^{-2}$ (Markowicz et al., 2008; Khatri et al., 2009; Wang et al., 2009; Kuhlmann and Quaas, 2010; Alam et al., 2011; Che et al., 2015c and so on). For example, the total aerosol DRF could be as strong as $-25 \mathrm{~W} \mathrm{~m}^{-2}$ over the Qinghai-Tibet Plateau (Kuhlmann and Quaas, 2010) and $-30 \mathrm{~W} \mathrm{~m}^{-2}$ in the North China Plain (Che et al., 2014, 2015c). Our results show that the aerosols in the urban area of the western YRD could also exert very strong DRFs, reaching as high as $-25.5 \mathrm{~W} \mathrm{~m}^{-2}$ at the surface. Apparently, the DRFs here have smaller uncertainties than those from the simulations because of the use of observations. They might be also more precise compared with previous estimations in Zhuang et al. (2014a). This study further investigated the size fractional DRFs of different aerosol components in urban areas of the western YRD, which allows a better understanding of the effects of aerosols on solar shortwave radiation. In addition, these issues have not been addressed in previous studies. The results here can also be used to validate numerical simulations and to evaluate model performances concerning aerosol radiative effects.

\subsubsection{Sensitivity of the aerosol direct radiative forcing to aerosol profiles}

Different aerosol profiles might result in different DRFs. Figure 14 presents the TOA and surface DRFs of different aerosol types, including the SA, AA and TA, based on four kinds of aerosol profiles from CALIPSO, PRL, the combined CALIPSO and PRL shown in Fig. 11 and the default one from TUV (Palancar and Toselli, 2004) in clear-sky conditions. The figure shows that the aerosol DRFs in clear-sky conditions are not very sensitive to the aerosol profile, although the absorbing aerosol TOA DRFs are more sensitive than those of the scattering aerosols. Overall, both the scattering and absorbing aerosol DRFs at the TOA become weaker to some extent when more aerosols are concentrated in the lower layers of the atmosphere, especially the AAs. Here, a profile impact factor (PIF) is defined as the ratio of the standard deviations among the four types of DRFs in Fig. 14 to the averaged values of these four DRFs. The PIF is approximately $4.97 \%$ for the absorbing aerosol TOA DRF and is below $2 \%$ for the rest of the types of DRFs. In contrast, the aerosol profiles might have much stronger influences on the DRFs in cloudy-sky conditions because the absorbing aerosols over brighter cloud will absorb more shortwave radiation (Podgorny and Ramanathan, 2001). This issue will be addressed in the future.

\subsubsection{Brief discussions}

Although the observation-based DRFs of the total, scattering and absorbing aerosols as well as their sensitivities to the aerosol profiles are analysed in this study, uncertainties still exist due to the measurement errors of the optical properties mentioned in Sect. 2. Additional estimations of the aerosol DRFs are carried out based on the errors of AOD, AAOD and SSAs. The results indicate that the greater uncertainties of the aerosol DRFs are mainly derived from the errors of SSA or AAOD. The uncertainties of the total aerosol AODs $(0.01)$ yield only approximately $1 \%$ relative biases for the total aerosol DRFs at both the TOA and surface. The total or fine-aerosol SSA errors (0.03 or 0.037) may result in approximately $24 \%$ of the uncertainties at the TOA $(<15 \%$ at the surface) for the corresponding DRFs. A larger coarseaerosol SSA error (0.085) leads to an $\sim 24 \%$ uncertainty of its surface DRFs. AAOD errors (0.01) cause approximately $20 \%$ of the uncertainties for the absorbing DRFs at both the TOA and surface while accounting for only $1.2 \%$ of the scat- 


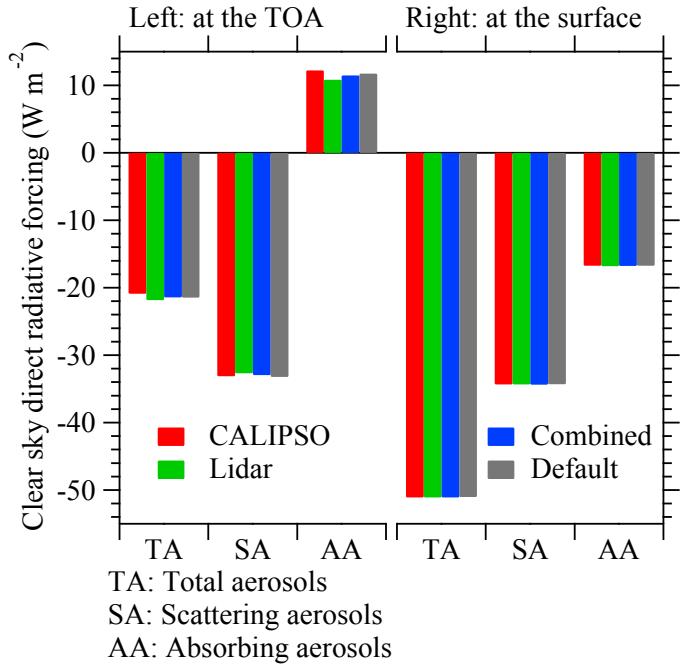

Figure 14. Sensitivities of the TOA and the surface aerosol DRFs (daytime, $\mathrm{W} \mathrm{m}^{-2}$ ) to the different aerosol profiles in clear conditions, for the total, scattering and absorbing aerosols.

tering DRFs uncertainties. Overall, these uncertainties are smaller than those presented in the 5th IPCC report (IPCC, 2013) and could be further decreased if the measurements or the algorithms were somewhat improved. For example, the absorbing aerosol DRFs would become more accurate if corresponding SSAs could be obtained by measurements. Also, the aerosol DRFs would be better estimated to a degree if its profiles with higher temporal resolution could be used in future. Additionally, extremely high aerosol loadings are frequently observed during serious pollution episodes, including dust storms, biomass burning and regional transport (Zhuang et al., 2014a, b, 2015). The aerosol optical and physical properties as well as the radiative forcing are different during these extreme episodes, which also deserves further study.

\section{Conclusions}

In this study, the size-dependent aerosol optical and physical properties observed by a Cimel sun photometer (CE-318) are investigated, as well as the corresponding DRFs calculated by the radiation transfer model TUV based on observations from the urban area of Nanjing (urNJ), western YRD.

In the urban area of the western YRD, the annual mean total aerosol AOD is 0.65 and is mostly due to the contribution of the scattering components (0.61). The absorption fraction is as small as $\sim 6.7 \%$. Approximately $80 \%$ of the aerosols in urNJ during the sampling period are fine-mode aerosols. The absorption fraction is approximately $4.6 \%$ in the fine mode and $15.5 \%$ in the coarse mode, showing the very different compositions and absorption characteristics of these two kinds of aerosols. Compared with the satellite retrievals, the observations show aerosol optical properties with much higher temporal resolutions and more products. Further analysis of the aerosol optical properties indicates that there might be approximately 15 and $27 \%$ occurrences of dust-dominated and BC-dominated mixing aerosols, respectively, in the western YRD during the study period.

The aerosols in the western YRD have a two-mode lognormal pattern in their volume size distribution, peaking at the radii of 0.148 and $2.94 \mu \mathrm{m}$ on an annual scale. The fine particles have the same contribution as the coarse ones when $\mathrm{AOD}<0.8$, and they become predominate when $0.8<\mathrm{AOD}<1.4$. In contrast to observations in other regions, the results here further reveal that the coarse aerosols might also induce very serious pollution episodes in the YRD. Both fine and coarse aerosols have the same levels of volume concentrations, although their radii differ by an order of magnitude.

Similarly to AODs, the total fine-aerosol DRFs have a high contribution to the totals, especially at TOA (>97\%), with a value of $-11.17 \mathrm{~W} \mathrm{~m}^{-2}$. However, differences exist. For each aerosol type, the coarse-aerosol DRF accounts for only $\sim 13.3 \%$ for the scattering aerosols but at least $33.7 \%$ for the absorbing aerosols at both the TOA and the surface in urNJ. The DRFs estimated for urNJ in this study are much stronger than their regional or global means.

Most of the size-dependent aerosol optical and physical properties as well as their DRFs have significant seasonality in the western YRD. The DRF variations for each aerosol type within the same mode are mostly consistent with the variations in the corresponding AODs, peaking in the summer for the fine aerosols and in the spring for the coarse ones. However, the variations in the total aerosol DRFs at the TOA are different from the corresponding AODs because the negative DRFs of the scattering aerosols are always offset by the absorbing aerosols. Both the fine and coarse aerosols have the largest sizes in the summer, which differs from the total aerosol mode (which peaks in the spring).

The sensitivities of clear-sky aerosol DRFs to the aerosol profiles are not significant and are all smaller than $5 \%$. Overall, both the scattering and absorbing aerosol DRFs at the TOA would become somewhat weaker if more aerosols were concentrated in the lower layers of the atmosphere, especially for the absorbed DRF. Further investigation suggests that another uncertainty of the DRFs is from the measuring errors of the aerosol optical properties. The larger biases are mainly derived from the errors of the SSA and AAOD.

Data availability. The monthly mean optical depth (AOD) and Ångström exponent (AE) of the total aerosols and surface albedo from the satellite-based Moderate Resolution Imaging Spectroradiometer (MODIS) are available at https://giovanni.gsfc.nasa. gov/giovanni/. The aerosol profile from the Cloud-Aerosol Lidar and Infrared Pathfinder Satellite Observations (CALIPSO) data sets are available at https://eosweb.larc.nasa.gov/project/calipso/ 
aerosol_profile_table. The TUV model is available at https://www2. acom.ucar.edu/modeling/tuv-download.

Competing interests. The authors declare that they have no conflict of interest.

Special issue statement. This article is part of the special issue "Regional transport and transformation of air pollution in eastern China". It is not associated with a conference.

Acknowledgements. This work was supported by the National Key R\&D Program of China (2017YFC0209803, 2014CB441203, 2016YFC0203303), the National Natural Science Foundation of China (41675143, 91544230, 41621005), and a project funded by the Priority Academic Program Development of the Jiangsu Higher Education Institutions (PAPD). The authors would like to thank all members in the AERC of Nanjing University for maintaining instruments, and also thank the anonymous reviewers for their constructive and valuable comments on this paper.

Edited by: Luisa Molina

Reviewed by: Junjun Deng and two anonymous referees

\section{References}

Alam, K., Trautmann, T., and Blaschke, T.: Aerosol optical properties and radiative forcing over mega-city Karachi, Atmos. Res., 101, 773-782, 2011.

Angström, A.: On the atmospheric transmission of sun radiation and on dust in the air, Geogr. Ann., 11, 156-166, 1929.

Arnott, W. P., Hamasha, K., Moosmuller, H., Sheridan, P. J., and Ogren, J. A.: Towards aerosol light-absorption measurements with a 7-wavelength aethalometer: evaluation with a photoacoustic instrument and 3-wavelength nephelometer, Aerosol Sci. Tech., 39, 17-29, https://doi.org/10.1080/027868290901972, 2005.

Bellouin, N., Boucher, O., Tanré, D., and Dubovik, O.: Aerosol absorption over the clear-sky oceans deduced from POLDER1 and AERONET observations, Geophys. Res. Lett., 30, 1748, https://doi.org/10.1029/2003GL017121, 2003.

Bergin, M. H., Cass, G. R., Xu, J., Fang, C., Zeng, L., Yu, T., Salmon, L. G., Kiang, C. S., Tang, X. Y., Zhang, Y. H., and Chameides, W. L.: Aerosol radiative, physical, and chemical properties in Beijing during June 1999, J. Geophys. Res., 106, 17969-17980, 2001.

Cai, H. K., Zhou, R. J., Fu, Y. F., Zheng, Y. Y., and Wang, Y. J.: Cloud-aerosol lidar with or thogonal polarization detection of aerosol optical properties after a crop burning case, Clim. Environ. Res., 16, 469-478, 2011.

Che, H., Wang, Y., and Sun, J.: Aerosol optical properties at Mt. Waliguan observatory, China, Atmos. Environ., 45, 6004-6009, 2011.

Che, H., Wang, Y., Sun, J., Zhang, X., Zhang, X., and Guo, J.: Variation of Aerosol Optical Properties over the Taklimakan Desert in China, Aerosol Air Qual. Res., 13, 777-785, 2013.
Che, H., Xia, X., Zhu, J., Li, Z., Dubovik, O., Holben, B., Goloub, P., Chen, H., Estelles, V., Cuevas-Agulló, E., Blarel, L., Wang, H., Zhao, H., Zhang, X., Wang, Y., Sun, J., Tao, R., Zhang, X., and Shi, G.: Column aerosol optical properties and aerosol radiative forcing during a serious haze-fog month over North China Plain in 2013 based on ground-based sunphotometer measurements, Atmos. Chem. Phys., 14, 2125-2138, https://doi.org/10.5194/acp-14-2125-2014, 2014.

Che, H., Zhang, X.-Y., Xia, X., Goloub, P., Holben, B., Zhao, H., Wang, Y., Zhang, X.-C., Wang, H., Blarel, L., Damiri, B., Zhang, R., Deng, X., Ma, Y., Wang, T., Geng, F., Qi, B., Zhu, J., Yu, J., Chen, Q., and Shi, G.: Ground-based aerosol climatology of China: aerosol optical depths from the China Aerosol Remote Sensing Network (CARSNET) 2002-2013, Atmos. Chem. Phys., 15, 7619-7652, https://doi.org/10.5194/acp15-7619-2015, 2015a.

Che, H., Xia, X., Zhu, J., Wang, H., Wang, Y., Sun, J., Zhang, X., and Shi, G.: Aerosol optical properties under the condition of heavy haze over an urban site of Beijing, China, Environ. Sci. Pollut. R., 22, 1043-1053, https://doi.org/10.1007/s11356-0143415-5, 2015b.

Che, H. Z., Zhao, H. J., Wu, Y. F., Xia, X. A., Zhu, J., Wang, H., Wang, Y. Q., Sun, J. Y., Yu, J., Zhang, X. Y., and Shi, G. Y.: Analyses of aerosol optical properties and direct radiative forcing over urban and industrial regions in Northeast China, Meteorol. Atmos. Phys., 127, 345-354, https://doi.org/10.1007/s00703-0150367-3, 2015c.

Che, H., Qi, B., Zhao, H., Xia, X., Eck, T. F., Goloub, P., Dubovik, O., Estelles, V., Cuevas-Agulló, E., Blarel, L., Wu, Y., Zhu, J., Du, R., Wang, Y., Wang, H., Gui, K., Yu, J., Zheng, Y., Sun, T., Chen, Q., Shi, G., and Zhang, X.: Aerosol optical properties and direct radiative forcing based on measurements from the China Aerosol Remote Sensing Network (CARSNET) in eastern China, Atmos. Chem. Phys., 18, 405-425, https://doi.org/10.5194/acp18-405-2018, 2018.

Chiang, C. W., Chen, W. N., Liang, W. A., Das, S. K., and Nee, J. B.: Optical properties of tropospheric aerosols based on measurements of lidar, sun-photometer, and visibility at Chung-Li $\left(25^{\circ} \mathrm{N}, 121^{\circ} \mathrm{E}\right)$, Atmos. Environ., 41, 4128-4137, https://doi.org/10.1016/j.atmosenv.2007.01.019, 2007.

Deng, J. J., Zhang, Y. R., Hong, Y. W., Xu, L. L., Chen, Y. T., Du, W. J., and Chen, J. S.: Optical properties of $\mathrm{PM}_{2.5}$ and the impacts of chemical compositions in the coastal city Xiamen in China, Sci. Total Environ., 557-558, 665-675, 2016.

Dong, Z. P., Li, X. M., Du, C. L., and, Zhang, G. J.: Study on aerosol optical property in Xi'An Region, Plateau Meteorology, 32, 856864, https://doi.org/10.7522/j.issn.1000-0534.2012.00079, 2013.

Dubovik, O. and King, M. D.: A flexible inversion algorithm for the retrieval of aerosol optical properties from Sun and sky radiance measurements, J. Geophys. Res., 105, 20673-20696, https://doi.org/10.1029/2000JD900282, 2000.

Dubovik, O., Sinyuk, A., Lapyonok, T., Holben, B. N., Mishchenko, M., Yang, P., Eck, T. F., Volten, H., Munoz, O., Veihelmann, B., van der Zande, W. J., Leon, J. F., Sorokin, M., and Slutsker, I.: Application of spheroid models to account for aerosol particle nonsphericity in remote sensing of desert dust, J. Geophys. Res.Atmos., 111, D11208, https://doi.org/10.1029/2005jd006619, 2006. 
Fan, X. H., Chen, H. B., Xia, X. A., Li, Z. Q., and Cribb, M.: Aerosol optical properties from the Atmospheric Radiation Measurement Mobile Facility at Shouxian. China, J. Geophys. Res., 115, D00K33, https://doi.org/10.1029/2010JD014650, 2010.

Forster, P., Ramaswamy, V., Artaxo, P., Berntsen, T., Betts, R., Fahey, D. W., Haywood, J., Lean, J., Lowe, D. C., Myhre, G., Nganga, J., Prinn, R., Raga, G., Schulz, M., and Van Dorland, R.: Changes in atmospheric constituents and in radiative forcing, in: Climate Change 2007: The Physical Science Basis, Contribution of Working Group I to the Fourth Assessment Report of the Intergovernmental Panel on Climate Change, edited by: Solomon, S., Qin, D., Manning, M., Chen, Z., Marquis, M., Averyt, K. B., Tignor, M., and Miller, H. L., Cambridge Univ. Press, Cambridge, UK, 129-234, 2007.

Hansen, A. D. A., Rosen, H., and Novakov, T.: The aethalometer: an instrument for the real time measurements of optical absorption by aerosol particles, Sci. Total Environ., 36, 191-196, 1984.

He, X., Li, C. C., Lau, A. K. H., Deng, Z. Z., Mao, J. T., Wang, M. H., and Liu, X. Y.: An intensive study of aerosol optical properties in Beijing urban area, Atmos. Chem. Phys., 9, 8903-8915, https://doi.org/10.5194/acp-9-8903-2009, 2009.

Holben, B. N., Eck, T. F., Slutsker, I., Tanre, D., Buis, J. P., Setzer, A., Vermote, E., Reagan, J. A., Kaufman, Y. J., Nakajima, T., Lavenu, F., Jankowiak, I., and Smirnov, A.: AERONET-a federated instrument network and data archive for aerosol characterization, Remote Sens. Environ., 66, 1-16, 1998.

Holler, R., Ito, K., Tohno, S., and Kasahara, M.: Wavelengthdependent aerosol single scattering albedo: measurements and model calculations for a coastal site near the sea of Japan during ACE-Asia, J. Geophys. Res., 108, 8648, https://doi.org/10.1029/2002JD003250, 2003.

IPCC 2013: Climate Change 2013: The Physical Science Basis, Contribution of Working Group I to the Fifth Assessment Report of the Intergovernmental Panel on Climate Change, edited by: Stocker, T. F., Qin, D., Plattner, G.-K., Tignor, M., Allen, S. K., Boschung, J., Nauels, A., Xia, Y., Bex, V., and Midgley, P. M., Cambridge University Press, Cambridge, UK and New York, NY, USA, 1535 pp., 2013.

Jacobson, M. Z.: A physically based treatment of elemental carbon optics: implication for global direct forcing of aerosols, Geophys. Res. Lett., 27, 217-220, 2000.

Jacobson, M. Z.: Control of fossil-fuel particulate black carbon and organic matter, possibly the most effective method of slowing global warming, J. Geophys. Res., 107, 4410, https://doi.org/10.1029/2001JD001376, 2002.

Jiang, Z., Liu, Z., Wang, T., Schwartz, C. S., Lin, H.-C., and Jiang, F.: Probing into the impact of 3DVAR assimilation of surface $\mathrm{PM}_{10}$ observations over China using process analysis, J. Geophys. Res.-Atmos., 118, 6738-6749, https://doi.org/10.1002/jgrd.50495, 2013.

Khatri, P., Ishizaka, Y., and Takamura, T.: A study on aerosol optical properties in an urban atmosphere of Nagoya, Japan, J. Meteorol. Soc. Jpn., 87, 19-38, 2009.

Kiehl, J. T. and Briegleb, B. P.: The relative roles of sulfate aerosols and greenhouse gases in climate forcing, Science, 260, 311-314, 1993.

Kuhlmann, J., and Quaas, J.: How can aerosols affect the Asian summer monsoon? Assessment during three consecutive pre-monsoon seasons from CALIPSO satellite data, At- mos. Chem. Phys., 10, 4673-4688, https://doi.org/10.5194/acp10-4673-2010, 2010.

Li, J., Carlson, B. E., and Lacis, A. A.: Using single-scattering albedo spectral curvature to characterize East Asian aerosol mixtures, J. Geophys. Res.-Atmos., 120, 2037-2052, 2015 a.

Li, J., Wang, W.-C., Liao, H., and Chang, W. Y.: Past and future direct radiative forcing of nitrate aerosol in East Asia, Theor. Appl. Climatol., 121, 445-458, 2015b.

Li, S., Wang, T. J., Xie, M., Han, Y., and Zhuang, B. L.: Observed aerosol optical depth and angstrom exponent in urban area of Nanjing, China, Atmos. Environ., 123, 350-356, https://doi.org/10.1016/j.atmosenv.2015.02.048, 2015.

Liao, H. and Seinfeld, J. H.: Global impacts of gas-phase chemistryaerosol interactions on direct radiative forcing by anthropogenic aerosols and ozone, J. Geophys. Res., 110, D18208, https://doi.org/10.1029/2005JD005907, 2005.

Ma, X. and Yu, F.: Effect of spectral dependent surface albedo on Saharan dust direct radiative forcing, Geophys. Res. Lett. 39, L09808, https://doi.org/10.1029/2012GL051360, 2012.

Ma, X. X., Liu, H. N., Liu, J., and Zhuang, B. L.: Sensitivity of climate effects of black carbon in China to its size distributions, Atmos. Res., 185, 118-130, 2017.

Madronich, S.: UV radiation in the natural and perturbed atmosphere, in: UV-B Radiation and Ozone Depletion, Effects on $\mathrm{Hu}-$ mans, Animals, edited by: Tevini, M., Plants, Microorganisms, and Materials, Lewis Publisher, Boca Raton, 17-69, 1993.

Markowicz, K. M., Flatau, P. J., Remiszewska, J., Witek, M., Reid, E. A., Reid, J. S., Bucholtz, Z., and Hilben, B.: Observations and modeling of the surface aerosol radiative forcing during UAE, J. Atmos. Sci. 65, 2877-2891, 2008.

Menon, S., Hansen, J., Nazarenko, L., and Luo, Y. F.: Climate effects of black carbon aerosols in China and India, Science, 297, 2250-2253, https://doi.org/10.1126/science.1075159, 2002.

Palancar, G. G. and Toselli, B. M.: Effects of meteorology and tropospheric aerosols on UV-B radiation: a 4-year study, Atmos. Environ., 18, 2749-2757, 2004.

Pan, L, Che, H. Z., Geng, F. H., Xia, X. A., Wang, Y. Q., Zhu, C. Z., Chen, M., Gao, W., and Guo, J. P.: Aerosol optical properties based on ground measurements over the Chinese Yangtze Delta Region, Atmos. Environ., 44, 2587-2596, https://doi.org/10.1016/j.atmosenv.2010.04.013, 2010.

Peng, Z., Liu, Z., Chen, D., and Ban, J.: Improving $\mathrm{PM}_{2.5}$ forecast over China by the joint adjustment of initial conditions and source emissions with an ensemble Kalman filter, Atmos. Chem. Phys., 17, 4837-4855, https://doi.org/10.5194/acp-174837-2017, 2017.

Penner, J. E., Andreae, M., Annegarn, H., Barrie, L., Feichter, J., Hegg, D., Jayaraman, A., Leaitch, R., Murphy, D., Nganga, J., and Pitari, G.: Aerosols, their direct and indirect effects, in: Climate Change 2001: The Scientific Basis, Contribution of Working Group I to the Third Assessment Report of the Intergovernmental Panel on Climate Change, edited by: Houghton, J. T., Ding, Y., Griggs, D. J., Noguer, M., van der Linden, P. J., Dai, X., Maskell, K., and Johnson, C. A., Cambridge University Press, Cambridge, UK and New York, NY, USA, 289-348, 2001.

Podgorny, I. A. and Ramanathan, V.: A modeling study of the direct effect of aerosols over the tropical Indian Ocean, J. Geophys. Res., 106, 24097-24105, 2001. 
Qi, B., Hu, D. Y., Che, H. Z., Du, R. G., Wu, Y. F., Xia, X. A., Zha, B., Liu, J., Niu, Y. W., Wang, H., Zhang, X. Y., and Shi, G. Y.: Seasonal variation of aerosol optical properties in an urban site of the Yangtze Delta Region of China, Aerosol Air Qual. Res., 16, 2884-2896, 2016.

Reddy, M. S., Boucher, O., Bellouin, N., Schulz, M., Balkanski, Y., Dufresne, J. L., and Pham, M.: Estimates of global multicomponent aerosol optical depth and direct radiative perturbation in the Laboratoire de Meteorologie Dynamique general circulation model, J. Geophys. Res., 110, D10S16, https://doi.org/10.1029/2004JD004757, 2005.

Russell, P. B., Kacenelenbogen, M., Livingston, J. M., Hasekamp, O. P., Burton, S. P., Schuster, G. L., Johnson, M. S., Knobelspiesse, K. D., Redemann, J., Ramachandran, S., and Holben, B.: A multiparameter aerosol classification method and its application to retrievals from spaceborne polarimetry, J. Geophys. Res.-Atmos., 119, 9838-9863, https://doi.org/10.1002/2013JD021411, 2014.

Sun, H., Pan, Z., and Liu, X.: Numerical simulation of spatialtemporal distribution of dust aerosol and its direct radiative effects on East Asian climate, J. Geophys. Res., 117, D13206, https://doi.org/10.1029/2011JD017219, 2012.

Tao, R., Che, H. Z., Chen, Q. L., Tao, J., Wang, Y. Q., Sun, J. Y., Wang, H., and Zhang, X. X.: Study of aerosol optical properties based on ground measurements over Sichuan Basin, China, Aerosol Air Qual. Res., 14, 905-915, https://doi.org/10.4209/aaqr.2012.07.0200, 2014.

Wang, T. J., Zhuang, B. L., Li, S., Liu, J., Xie, M., Yin, C. Q., Zhang, Y., Yuan, C., Zhu, J. L., Ji, L. Q., and Han, Y.: The interactions between anthropogenic aerosols and the East Asian summer monsoon using RegCCMS, J. Geophys. Res.-Atmos., 120, 5602-5621, https://doi.org/10.1002/2014JD022877, 2015.

Wang, Y., Che, H. Z., Ma, J. Z., Wang, Q., Shi, G. Y., Chen, H. B., Goloub, P., and Hao, X. J.: Aerosol radiative forcing under clear, hazy, foggy, and dusty weather conditions over Beijing, China, Geophys. Res. Lett., 36, L06804, https://doi.org/10.1029/2009GL037181, 2009.

Weingartner, E., Saathoff, H., Schnaiter, M., Streit, N., Bitnar, B., and Baltensperger, U.: Absorption of light by soot particles: determination of the absorption coefficient by means of aethalometers, J. Aerosol Sci., 34, 1445-1463, https://doi.org/10.1016/S0021-8502(03)00359-8, 2003.

Wu, Y. F., Zhang, R. J., Pu, Y. F., Zhang, L. M., Ho, K. F., and Fu, C. B.: Aerosol optical properties observed at a semi-arid rural site in northeastern China, Aerosol Air Qual. Res., 12, 503-514, 2012.

Xia, X. A., Li, Z. Q., Holben, B., Wang, P., Eck, T., Chen, H. B., Cribb, M., and Zhao, Y. X.: Aerosol optical properties and radiative effects in the Yangtze Delta region of China, J. Geophys. Res., 112, D22S12, https://doi.org/10.1029/2007JD008859, 2007.

Xia, X., Che, H., Zhu, J., Chen, H., Cong, Z., Deng, X., Fan, X., Fu, Y., Goloub, P., Jiang, H., Liu, Q., Mai, B., Wang, P., Wu, Y., Zhang, J., Zhang, R., and Zhang, X.: Ground-based remote sensing of aerosol climatology in China: aerosol optical properties, direct radiative effect and is parameterization, Atmos. Environ., 214, 243-251, https://doi.org/10.1016/j.atmosenv.2015.05.071, 2016.

Xu, J., Bergin, M. H., Yu, X., Liu, G., Zhao, J., Carrico, C. M., and Baumann, K.: Measurement of aerosol chemical, physical and radiative properties in the Yangtze delta region of China, Atmos. Environ., 36, 161-173, 2002.

Xu, J., Tao, J., Zhang, R., Cheng, T., Leng, C., Chen, J., Huang, G., Li, X., and Zhu, Z.: Measurements of surface aerosol optical properties in winter of Shanghai, Atmos. Res., 109-110, 25-35, 2012.

$\mathrm{Xu}, \mathrm{X}$ : Retrieval of aerosol microphysical properties from AERONET photolarimetric measurements, PhD diss., Department of Earth and Atmospheric Sciences, University of Nebraska-Lincoln, 2015.

Yan, P., Tang, J., Huang, J., Mao, J. T., Zhou, X.J., Liu, Q., Wang, Z. F., and Zhou, H. G.: The measurement of aerosol optical properties at a rural site in Northern China, Atmos. Chem. Phys., 8, 2229-2242, https://doi.org/10.5194/acp-8-2229-2008, 2008.

Yu, J., Che, H. Z., Chen, Q. L., Xia, X. A., Zhao, H. J., Wang, H., Wang, Y. Q., Zhang, X. X., and Shi, G. Y.: Investigation of aerosol optical depth (AOD) and Ångström exponent over the desert region of northwestern China based on measurements from the China Aerosol Remote Sensing Network (CARSNET), Aerosol Air Qual. Res., 15, 2024-2036, https://doi.org/10.4209/aaqr.2014.12.0326, 2015.

Yu, X. N., Ma, J., Kumar, K. R., Zhu, B., An, J. L., He, J. Q., and Li, M.: Measurement and analysis of surface aerosol optical properties over urban Nanjing in the Chinese Yangtze River Delta, Sci. Total Environ., 542, 277-291, 2016.

Yu, X. N., Zhu, B., Yin, Y., Fan, S. X., and Chen, A. J.: Seasonal variation of columnar aerosol optical properties in Yangtze River Delta in China, Adv. Atmos. Sci., 28, 1326-1335, https://doi.org/10.1007/s00376-011-0158-9, 2011.

Zhang, L., Sun, J. Y., Shen, X. J., Zhang, Y. M., Che, H., Ma, Q. L., Zhang, Y. W., Zhang, X. Y., and Ogren, J. A.: Observations of relative humidity effects on aerosol light scattering in the Yangtze River Delta of China, Atmos. Chem. Phys., 15, 84398454, https://doi.org/10.5194/acp-15-8439-2015, 2015.

Zhang, Q., Streets, D. G., Carmichael, G. R., He, K. B., Huo, H., Kannari, A., Klimont, Z., Park, I. S., Reddy, S., Fu, J. S., Chen, D., Duan, L., Lei, Y., Wang, L. T., and Yao, Z. L.: Asian emissions in 2006 for the NASA INTEX-B mission, Atmos. Chem. Phys., 9, 5131-5153, https://doi.org/10.5194/acp-9-5131-2009, 2009.

Zhang, W., Hu, B., Chen, C. H., Du, P., Zhang, L., and Feng, G. H.: Scattering properties of atmospheric aerosols over Lanzhou City and applications using an integrating nephelometer, Adv. Atmos. Sci., 21, 848-856, 2004.

Zhang, X. Y., Wang, Y. Q., Niu, T., Zhang, X. C., Gong, S. L., Zhang, Y. M., and Sun, J. Y.: Atmospheric aerosol compositions in China: Spatial/temporal variability, chemical signature, regional haze distribution and comparisons with global aerosols, Atmos. Chem. Phys., 12, 779-799, https://doi.org/10.5194/acp12-779-2012, 2012.

Zhao, H. J., Che, H. Z., Zhang, X. Y., Ma, Y. J., Wang, Y. F., Wang, X. X., Liu, C., Hou, B., and Che, X. C.: Aerosol optical properties over urban and industrial region of Northeast China by using ground-based sun-photometer Measurement, Atmos. Environ., 75, 270-278, https://doi.org/10.1016/j.atmosenv.2013.04.048, 2013.

Zheng, Y., Che, H. Z., Zhao, T. L., Xia, X. A., Gui, K., An, L. C., Qi, B., Wang, H., Wang, Y. Q., Yu, J., and Zhang, X. Y.: Aerosol Optical Properties over Beijing during the 
World Athletics Championships and Victory Day Military Parade in August and September 2015, Atmosphere, 7, 47, https://doi.org/10.3390/atmos7030047, 2016.

Zhu, J., Che, H. Z., Xia, X. A., Chen, H. B., Goloub, P., and Zhang, W. X.: Column-integrated aerosol optical and physical properties at a regional background atmosphere in North China Plain, Atmos. Environ., 84, 54-64, https://doi.org/10.1016/j.atmosenv.2013.11.019, 2014.

Zhu, J., Wang, T., Talbot, R., Mao, H., Hall, C. B., Yang, X., Fu, C., Zhuang, B., Li, S., Han, Y., and Huang, X.: Characteristics of atmospheric Total Gaseous Mercury (TGM) observed in urban Nanjing, China, Atmos. Chem. Phys., 12, 12103-12118, https://doi.org/10.5194/acp-12-12103-2012, 2012.

Zhuang, B., Wang, T., Liu, J., Li, S., Xie, M., Han, Y., Chen, P., Hu, Q., Yang, X.-Q., Fu, C., and Zhu, J.: The surface aerosol optical properties in the urban area of Nanjing, west Yangtze River Delta, China, Atmos. Chem. Phys., 17, 11431160, https://doi.org/10.5194/acp-17-1143-2017, 2017.

Zhuang, B. L., Li, S., Wang, T. J., Deng, J. J., Xie, M., Yin, C. Q., and Zhu, J. L.: Direct radiative forcing and climate effects of anthropogenic aerosols with different mixing states over China, Atmos. Environ., 79, 349-361, https://doi.org/10.1016/j.atmosenv.2013.07.004, 2013a.
Zhuang, B. L., Liu, Q., Wang, T. J., Yin, C. Q., Li, S., Xie, M., Jiang, F., and Mao, H. T.: Investigation on semidirect and indirect climate effects of fossil fuel black carbon aerosol over China, Theor. Appl. Climatol., 114, 651-672, https://doi.org/10.1007/s00704-013-0862-8, 2013 b.

Zhuang, B. L., Wang, T. J., Li, S., Liu, J., Talbot, R., Mao, H. T., Yang, X. Q., Fu, C. B., Yin, C. Q., Zhu, J. L., Che, H. Z., and Zhang, X. Y.: Optical properties and radiative forcing of urban aerosols in Nanjing, China, Atmos. Environ., 83, 43-52, 2014a.

Zhuang, B. L., Wang, T. J., Liu, J., Li, S., Xie, M., Yang, X. Q., Fu, C. B., Sun, J. N., Yin, C. Q., Liao, J. B., Zhu, J. L., and Zhang, Y.: Continuous measurement of black carbon aerosol in urban Nanjing of Yangtze River Delta, China, Atmos. Environ., 89, 415-424, 2014b.

Zhuang, B. L., Wang, T. J., Liu, J., Ma, Y., Yin, C. Q., Li, S., Xie, M., Han, Y., Zhu, J. L., Yang, X. Q., and Fu, C. B.: Absorption coefficient of urban aerosol in Nanjing, west Yangtze River Delta, China, Atmos. Chem. Phys., 15, 13633-13646, https://doi.org/10.5194/acp-15-13633-2015, 2015. 